Elsevier Editorial system(tm) for

International Journal of Hydrogen Energy

Manuscript Draft

Manuscript Number: HE-D-18-02973R1

Title: Bimetallic $\mathrm{Cu}-\mathrm{Ni}$ catalysts for the WGS reaction - cooperative or uncooperative effect?

Article Type: Full Length Article

Section/Category: Hydrogen Economy / Commercialization

Keywords: water-gas shift reaction, bimetallic catalysts, Cu-Ni, synergy, anti-synergy

Corresponding Author: Dr. Laura Pastor-Pérez, PhD in Chemistry

Corresponding Author's Institution: University of Alicante

First Author: Laura Pastor-Pérez, PhD in Chemistry

Order of Authors: Laura Pastor-Pérez, PhD in Chemistry; Sai Gu, Professor of Chemical Engineering; Antonio Sepulveda-Escribano, Professor of Inorganic Chemistry; Tomas Ramirez Reina, PhD in Chemistry

Abstract: In this work, bimetallic Cu-Ni catalysts have been studied in the water-gas shift (WGS) reaction, and they have shown different levels of synergy and anti-synergy in terms of catalytic activity and selectivity to the desired products. Cu-Ni interactions alter the physicochemical properties of the prepared materials (i.e. surface chemistry, redox behaviour, etc.) and as a result, the catalytic trends are influenced by the catalysts' composition. Our study reveals that Cu enhances $\mathrm{Ni}$ selectivity to $\mathrm{CO} 2$ and $\mathrm{H} 2$ by preventing CO/CO2 methanation, while $\mathrm{Ni}$ does not help to improve $\mathrm{Cu}$ catalytic performance by any means. Indeed, the monometallic Cu formulation has shown the best results in this study, yielding high levels of reactants conversion and excellent long-term stability. Interestingly, for medium-high temperatures, the bimetallic $1 \mathrm{Cu}-1 \mathrm{Ni}$ outperforms the stability levels reached with the monometallic formulation and becomes an interesting choice even when start-up/shutdowns operations are considered during the catalytic experiments. 


\section{SURREY}

Faculty of Engineering \& Physical Sciences

Department of Chemical \& Process Engineering Guildford, Surrey,

GU2 7XH, UK

\section{Dr Laura Pastor Pérez}

MChem, MSc, PhD

l.pastorperez@surrey.ac.uk

Guildford, 02 July 2018

Dear editor,

We are delighted to propose to you our latest study entitled: "Bimetallic CU-Ni catalysts for the WGS reaction - cooperative or uncooperative effect?" by the authors, L. Pastor-Pérez, S. Gu, A. SepúlvedaEscribano and T. R. Reina.

In this work, we have developed and compared a series of highly robust catalysts for efficient $\mathrm{H}_{2}$ production via water-gas shift reaction (WGS). The materials employed were monometallic and bimetallic nickel-copper based catalysts supported on ceria-alumina.

We have analysed the influence of adding $\mathrm{Cu}$ to a $\mathrm{Ni} / \mathrm{CeO}_{2}-\mathrm{Al}_{2} \mathrm{O}_{3}$ catalyst and $\mathrm{Ni}$ to a $\mathrm{Cu} / \mathrm{CeO} \mathrm{O}_{2}-\mathrm{Al}_{2} \mathrm{O}_{3}$ catalyst, as well as the impact of the $\mathrm{Ni} / \mathrm{Cu}$ ratio on the catalytic activity, selectivity (suppression of methanation reaction) and stability during the WGS. Moreover, we examined the different advantages for bimetallic/monometallic formulations in a broadband temperature range as it is very desirable to intensify the WGS process by using only one reaction unit in which the catalyst can operate in a wider temperature range.

Regarding bimetallic $\mathrm{Ni}-\mathrm{Cu}$ formulations, we found that the incorporation of small amounts of $\mathrm{Cu}$ formed the Cu-Ni alloy and suppressed the undesired methanation reaction. In particular, the $1 \mathrm{Cu} 1 \mathrm{Ni} / \mathrm{CeAl}$ catalyst presented the highest levels of CO conversion at higher temperatures.

Interestingly, the monometallic Cu-based catalyst was the best system within the studied series since it exhibited high levels of $\mathrm{CO}$ conversion in the whole temperature range with null selectivity to methane and excellent stability for continuous operation and start/stop cycles. Furthermore, the advanced behaviour of our $\mathrm{Cu}-\mathrm{CeO}_{2}-\mathrm{Al}_{2} \mathrm{O}_{3}$ mixtures overcame the space velocity restrictions of this metal in the WGS reaction. 
Hence, this work presents an interesting discussion and remarkable scientific contribution and we consider that it fits well with the scope of International Journal of Hydrogen Energy so that we are happy to propose it for consideration for publication.

Looking forward to receiving your reply,

Kind regards,

Dr Laura Pastor Pérez 
Dr. Miriam Navlani Garcia

Posdoctoral Fellow, PhD

miriam@mat.eng.osaka-u.ac.jp

Osaka University | Handai Division of Materials and Manufacturing Science, Graduate School of Engineering

Dr. Svetlana Ivanova

svetlana@icmse.csic.es

Departamento de Química Inorgánica, Universidad de Sevilla e Instituto de Ciencias de Materiales de Sevilla Centro Mixto US-CSIC Avda, Américo Vespucio 49, 41092 Seville, Spain

Dr Salvador Eslava

Lecturer

s.eslava@bath.ac.uk

Department of Chemical Engineering

University of Bath 


\section{Dear editor,}

We are pleased to present the response to the reviewers' comments for the paper entitled "Bimetallic Cu-Ni catalysts for the WGS reaction - cooperative or uncooperative effect?' We have addressed all the points suggested by the referees. Some parts of the manuscript have been reoriented and all the modifications are highlighted in the revised manuscript. Some of the main changes are:

- New long-term stability test - Figure 8

- New Table 3 including a comparison with state of art materials published in the literature

- Quantitative Analysis of the TPR profiles

- Textural properties study (Table 1)

- Some new references have been included and the list of references has been renumbered.

Reviewer \#1: This is a short manuscript which deals with an interest topic but presents very few original conclusions on the $\mathrm{Cu}-\mathrm{Ni}-\mathrm{Ce}$ catalytic system for the Water-gas Shift reaction. In addition, several results presented here cannot be explained by the analysis conducted. As a consequence, I do not recommend this manuscript for being published in its present form.

Concerning TPR experiments, Authors' affirmations about peak assignment ("Ni reduction accompanied by the reduction of ceria", "bulk $\mathrm{CuO}$ particles and surface $\mathrm{CeO} 2$ interacting to the different extent", etc) are not at all supported by stoichiometric calculations from $\mathrm{H} 2$ peak consumption integration. Without those calculations, peak assignment presented are just interpretations from data obtained in temperature programmed reduction experiments of other works. Even more, the improvement of reducibility of $\mathrm{NiO}$ when $\mathrm{CuO}$ is added is an already known result for these catalytic systems.

We appreciate the useful comment of the referee in our TPR experiments and following his/her suggestion we have substantially improved this section. We have performance stoichiometric calculations to obtain the total reducibility (\%R) of the different samples. The results provide insightful information regarding the redox behaviour of our catalysts. We have added a Table to Figure 2 and re-discussed this section.

\begin{tabular}{lcc}
\hline \multicolumn{1}{c}{ Samples } & $\mathbf{H}_{\mathbf{2}}$ mols $_{\exp }$ & $\mathbf{R}(\%)$ \\
\hline $\mathrm{Ni} / \mathrm{CeAl}$ & $3,49 \mathrm{E}-04$ & 47 \\
$1 \mathrm{Cu} 2 \mathrm{Ni} / \mathrm{CeAl}$ & $5,33 \mathrm{E}-04$ & 72 \\
$1 \mathrm{Cu} 1 \mathrm{Ni} / \mathrm{CeAl}$ & $5,20 \mathrm{E}-04$ & 70 \\
$2 \mathrm{Cu} 1 \mathrm{Ni} / \mathrm{CeAl}$ & $4,94 \mathrm{E}-04$ & 67 \\
$\mathrm{Cu} / \mathrm{CeAl}$ & $5,43 \mathrm{E}-04$ & 74 \\
\hline
\end{tabular}

The catalytic behaviour shown in Figure 5 reveals a trend in bimetallic samples that is difficult to understand. Pure Ni catalyst is better than any of these samples but, in contrast, the bimetallic sample containing more nickel (1Cu2Ni) is less active than the others. XPS and XRD experiments 
predict copper segregation at high copper loading but, on the contrary, the weak activity of this high Ni content sample is not discussed.

The catalytic behaviour of our materials is relatively complex and must be look as a conjunction of activity at a low/high temperature in the WGS reaction, selectivity (suppression of methanation) and synergistic effects of the active phases (bimetallic materials). The monometallic Ni catalyst is "apparently" more active than the bimetallic systems (it does convert more CO2) but it produces methane. Therefore is substantially less selective.

For the 1Cu2Ni sample, the synergic effect due to $\mathrm{Cu}-\mathrm{Ni}$ interaction is not as notorious as for the $1 \mathrm{Cu} 1 \mathrm{Ni} / \mathrm{CeAl}$ sample as can be seen from the XPS data. We can see that its conversion is similar to that of the $2 \mathrm{Cu} 1 \mathrm{Ni} / \mathrm{CeAl}$ sample (having both opposite compositions)

The $1 \mathrm{Cu} 2 \mathrm{Ni} / \mathrm{CeAl}$ sample has an intermediate behaviour as could be expected. If we compare it with the opposite sample, $2 \mathrm{Cu} 1 \mathrm{Ni} / \mathrm{CeAl}$, It has better catalytic behaviour at high temperatures due to the higher amount on $\mathrm{Ni}$ in this sample, but it has a lower catalytic conversion at lower temperatures being better the $2 \mathrm{Cu} 1 \mathrm{Ni} / \mathrm{CeAl}$ sample for its higher amount of $\mathrm{Cu}$ present. They follow the same trend that their monometallic counterparts.

Other minor issues related to catalytic experiments are: 1 ) why a water to CO ratio $5: 1$ is chosen, being the stoichiometric ratio 1:1? (have the Authors tested other values at the reactor feed);

As it was mention in the "2.3 Catalytic activity" section the high amount of water used is because we want to simulate a post reforming stream. Indeed working in steam-rich atmospheres is a comment practice in the WGS especially when the shift reactor is envisaged to run in a hydrogen fuel processor, saving space and capital cost of implementing a water condenser after the reforming unit. Many works in literature can be found with similar concentrations of steam for in the WGS tests (see for instance Applied Catalysis B: Environmental 238 (2018) 1-5; Applied Catalysis B: Environmental 101 (2011) 266-274; Journal of Catalysis (2014) 314, 1-9; etc.)

2) In the legend of Figure 6, which is the composition of a "post-reforming" mixture;

This is explained in "2.3 Catalytic activity" section. A post reforming mixture is a feed stream composed by the gases present in the outlet of a reforming reactor. A typical composition is that used in this paper consisting of $25 \%$ vol. $\mathrm{H}_{2} \mathrm{O}+8 \%$ vol. $\mathrm{CO}, 37 \% \mathrm{H}_{2}$ and $8 \% \mathrm{CO}_{2}$.

Following the reviewer suggestion, we have added the composition in Figure 6's caption.

3) Figure 6 should include the equilibrium curve for the case where methanation reaction could take place.

The methanation reaction is in fact included in the current equilibrium which accounts for the $\mathrm{CO}$ converted via WGS and methanation reaction. Including the potential production of methane in the figure could be confusing and also the methanation equilibrium in the studied conditions is wellknown. However, we have made stronger emphasis in the discussion to account for this matter as pointed out by the reviewer. 
Regarding the long-term stability test shown in Figure 7, there is a complete lack of characterization of the spent samples (metallic area, Cu crystallite size, dispersion, etc) which could have triggered further analysis of the role of Cu sintering on samples' deactivation.

Following referee suggestions, we have conducted XRD analysis for $\mathrm{Cu} / \mathrm{CeAl}$ spend sample after the stability test.

The deactivation smooth deactivation observed is very likely related to $\mathrm{Cu}$ particles sintering. Indeed, we have calculated (using Scherrer equation) the Cu crystallite size of the Cu/CeAl sample before (reduced sample) and after being tested it in the stability test. Cu metallic cluster presents a particle size of $15 \mathrm{~nm}$ in the reduced sample (diffractogram showed in Figure 1 (b)). After the $230 \mathrm{~h}$ of stability test with several start/stop cycles, the metallic $\mathrm{Cu}$ suffered a slight degree of sintering leading to particle sizes of $31 \mathrm{~nm}$ (diffractogram not shown) Also, very small diffraction peaks related to $\mathrm{CuO}$ appear after this stability test. The later could be due to the start-stop cycles where metallic $\mathrm{Cu}$ may undergo partial oxidation caused by interaction with liquid water during the shutdown stages. Both reasons (a certain degree of sintering and partial oxidation) account for the continuous activity depletion observed during the $230 \mathrm{~h}$ stability test.

Finally, in "Conclusions", Authors stated that "the bimetallic catalyst is more interesting than the monometallic $\mathrm{Ni}$ if the $\mathrm{Cu}-\mathrm{Ni}$ alloy is achieved, since the alloy suppresses the unwanted parallel methanation reaction which consumes hydrogen". In addition to the fact that this is a reported result, see Poggio-Fraccari et al / Applied Catalysis A: General 460-461 (2013) 15-20, Authors should clearly precise which is the goal of their research work. If WGS reaction is meant to reduce $\mathrm{CO}$ level, then $\mathrm{CO}$ methanation is not an undesired reaction (but if the aim of the process is to obtain hydrogen, then hydrogen consumption via methanation reaction should be avoided).

The paper by Poggio-Fraccari et al is an interesting study indeed although we believe there are substantial differences with our work - for instance, they use a Pr-doped ceria as a support which plays a role in the reaction. Also, they use $1 \mathrm{Cu}-1 \mathrm{Niand} 1 \mathrm{Cu}-3 \mathrm{Ni}$ samples and observed that the 1-3 is the best combination.

Our main target is to develop highly efficient WGS catalysts for hydrogen fuel processors therefore hydrogen consumption via CO-methanation is an undesired reaction and must be suppressed. For the goal, the monometallic sample based on $\mathrm{Cu}$ is the more advantageous compared to bi-metallic despite the efforts trying to improve the formulation including $\mathrm{Ni}$ (by our work and some other groups) We have modified the conclusions and the abstract according to the referees' comments.

Reviewer \#2: This paper reported mono and bimetallic $\mathrm{Cu}-\mathrm{Ni}$-based catalysts behavior in water gas shift reaction. This work is well organized, and could be accepted for publication. However, there are still some issues that need to be addressed:

1. The abstract and conclusions do not support the results.

We have revised abstract and conclusions following the referee's suggestion. 
2. The reviewer would like to suggest the authors to elaborate the introduction with recently published articles. For the sake of completeness, the following articles can be cited in the manuscript. (a) chemical engineering research and design 113 ( 2016 ) 9-16, (b) RSC Adv., 2015, 5, 9955, and (c) Ind. Eng. Chem. Res. 2015, 54, 1236-1242.

We thank the referee for his input in the literature review and we have included two of these references in the manuscript as references 4 and 6 . They are in fact very relevant to this work.

3. The reviewer suggests that the author provide the catalyst some other characterization results (BET, SEM, TEM and so on) and discriminate the structural properties of the support and the other metals included in the present composite catalytic material.

We appreciate the comment of the referee and we have included a full textural properties study

Table 1. Textural properties of supports and catalysts.

\begin{tabular}{|l|c|c|c|}
\hline Samples & $\mathrm{BET}\left(\mathrm{m}^{2} / \mathrm{g}\right)$ & $\begin{array}{c}\text { Total Pore Volume } \\
\left(\mathrm{cm}^{3} / \mathrm{g}\right)\end{array}$ & Pore Size $(\mathrm{nm})$ \\
\hline $\mathrm{Al}_{2} \mathrm{O}_{3}$ & 216 & 0.513 & 6.15 \\
\hline $\mathrm{CeO}_{2}-\mathrm{Al}_{2} \mathrm{O}_{3}$ & 159 & 0.361 & 6.14 \\
\hline $\mathrm{Ni} / \mathrm{CeAl}$ & 141 & 0.308 & 6.14 \\
\hline $1 \mathrm{Cu} 2 \mathrm{Ni} / \mathrm{CeAl}$ & 139 & 0.300 & 6.12 \\
\hline $1 \mathrm{Cu} 1 \mathrm{Ni} / \mathrm{CeAl}$ & 138 & 0.306 & 6.12 \\
\hline $2 \mathrm{Cu} 1 \mathrm{Ni} / \mathrm{CeAl}$ & 134 & 0.302 & 6.03 \\
\hline $\mathrm{Cu} / \mathrm{CeAl}$ & 115 & 0.297 & 6.04 \\
\hline
\end{tabular}

Table 1 provides the textural properties of the bare $\mathrm{Al}_{2} \mathrm{O}_{3}, \mathrm{CeO}_{2}-\mathrm{Al}_{2} \mathrm{O}_{3}$ support and all the synthesised catalysts. All the supports and their corresponding $\mathrm{Ni}, \mathrm{Ni}-\mathrm{Cu}$ and $\mathrm{Cu}$ catalysts exhibit type IV isotherms (not shown), typically ascribed to mesoporous materials according to IUPAC classifications. The surface areas of the prepared materials ranged from $115-216 \mathrm{~m}^{2} \mathrm{~g}^{-1}$ while the primary pore diameters estimated from the maximum in the BJH pore size distribution are around 6 $\mathrm{nm}$. The textural properties are governed by the primary $\mathrm{Y}$-alumina support. The expected decrease in surface area and pore volume after metal and oxide introduction is related to partial blockage of pores of the $\mathrm{Al}_{2} \mathrm{O}_{3}$ support and dilution effect due to the high metal loading. Overall changes on the textural properties within the studied series are not remarkable and in principle, we do not expect an impact of the textural features on the catalytic performance.

4. The authors claimed that $\mathrm{Cu}$ enhances $\mathrm{Ni}$ selectivity to $\mathrm{CO} 2$ and $\mathrm{H} 2$ by preventing $\mathrm{CO} / \mathrm{CO} 2$ methanation. That is right but the methane concentration or methane selectivity should be reported for better comparison.

No methane formation was observed for any bimetallic Cu-Ni catalysts and for the monometallic $\mathrm{Cu}$ catalyst and it was remarked already in the manuscript "For the rest of the samples (bimetallic $\mathrm{Cu}-\mathrm{Ni}$ and monometallic $\mathrm{Cu}$ ) no methane formation was detected." Only for the $\mathrm{Ni} / \mathrm{CeAl}$ sample methane was formed starting at $280{ }^{\circ} \mathrm{C}$ with $1 \%$ of methane reaching a $5 \%$ at $320 \mathrm{C}$. We have added these data in the discussion as per advised by the referee.

5. It is seen that the Cu catalyst showed partially decline in CO conversion. It would be better that the long term stability of the bimetallic $\mathrm{Ni}-\mathrm{Cu}$ catalysts was also investigated to find out the role of $\mathrm{Ni}$ on the stability of the Cu catalyst. 
We only tested $\mathrm{Cu}$ monometallic catalysts in our study because we wanted to focus on the medium-temperature shift reaction catalyst. At $280 \stackrel{\circ}{\circ}$ (temperature chosen for the stability tests) the $1 \mathrm{Ni}-1 \mathrm{Cu} / \mathrm{CeAl}$ catalyst has not significant $\mathrm{CO}$ conversion (less than $10 \%$ ).

However and since we believe that the referee's comment is interesting we have tested the stability of a selected bimetallic sample at a higher temperature $(340 \mathrm{C})$ - see new figure 8 and its corresponding discussion.

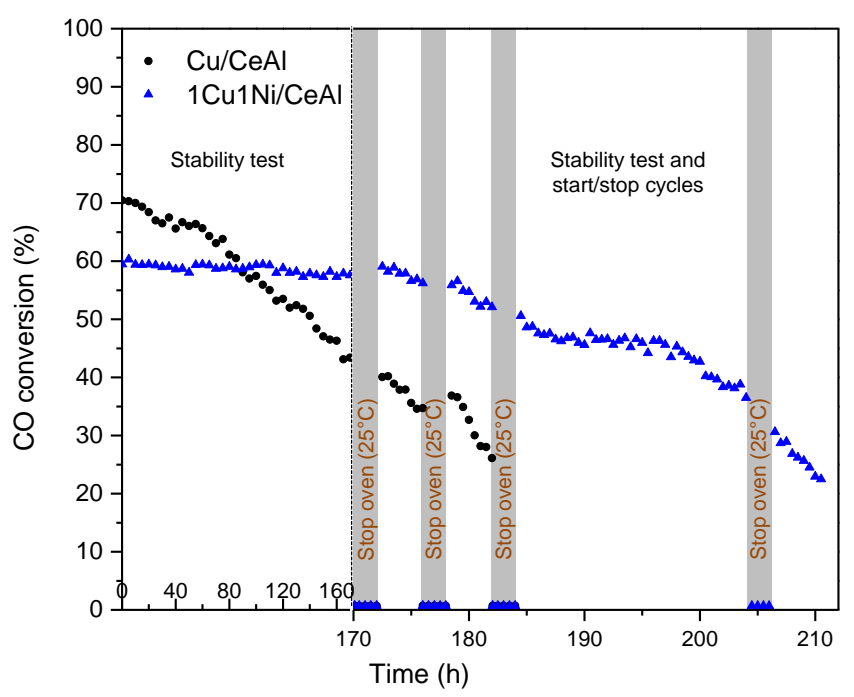

Figure 8. Long-term stability runs at $340^{\circ} \mathrm{C}$, including some start/stop cycles for the $\mathrm{Cu} / \mathrm{CeAl}$ and $1 \mathrm{Cu} 1 \mathrm{Ni} / \mathrm{CeAl}$ catalysts.

A comparative long-term stability test of the monometallic and bimetallic (1:1) sample was conducted including some start-stop cycles during the reaction. As shown in the figure the monometallic suffers for a clear activity decline even before the start-up/shutdowns operations. In fact, at this temperature Cu sintering is more favoured than in the previous experiments in Figure 7 and therefore there is a significantly stronger deactivation. Very interestingly, the bimetallic material is quite robust and displays a very stable behaviour during $160 \mathrm{~h}$ of reaction. However, upon performing 3 initial start-stop cycles the activity drops from around $60 \%$ of $\mathrm{CO}$ conversion to ca. $47 \%$ and then after the a final cycle at $205 \mathrm{~h}$ the catalyst remarkably loss its activity. In any case, the superior stability of the bimetallic sample compared to the monometallic one reflects the benefits of the Cu-Ni interaction which seems to go beyond an electronic effect as shown in our XPS data but also such synergy may help to prevent $\mathrm{Cu}$ clusters sintering leading to enhanced stability.

6. The comparison of present activity results with the results of other similar investigations in literature should be discussed in detail. This is needed to place this work in perspective with other works in the field and provide more credibility for the present results.

We agree with the referee and we have added a new table (Table 3) containing a relevant comparison of our catalysts with benchmark materials, bimetallic $\mathrm{Cu}-\mathrm{Ni}$ catalysts and also noble metals based catalysts. It must be stated that such a comparison is not always straightforward and the elaboration of this table has been a tedious task given the multiple reaction conditions employed in available works in literature. Herein we have selected those works that employed 
similar reaction conditions as ours. As shown in the table the catalysts presented in this study can be ranked as high performing catalysts for the medium temperature shift reaction. Clearly, benchmark catalysts and noble metal based system outperform our materials in the lowtemperature range, however, our mono and bi-metallic catalysts are very efficient for temperatures above $300 \mathrm{C}$ and clearly more efficient than other bimetallic $\mathrm{Cu}-\mathrm{Ni}$ systems reported in the literature.

\begin{tabular}{|c|c|c|c|c|c|}
\hline Catalyst & Temp. range & Gas mixture & CO conversion & GHSV $\left(h^{-1}\right)$ & Reference \\
\hline $\begin{array}{l}10 \%- \\
(5 \mathrm{Cu} 5 \mathrm{Ni}) @ \mathrm{CeO}_{2} \\
\text { (shell catalyst) }\end{array}$ & $300-500$ & $\begin{array}{l}5 \text { mol\% } \mathrm{CO}, 25 \\
\text { mol\% } \mathrm{H}_{2} \mathrm{O} \\
\text { balanced in } \mathrm{He}\end{array}$ & $\begin{array}{l}\text { Highest CO } \\
\text { conversion }(92 \%) \text { achieved } \\
\text { at } 500{ }^{\circ} \mathrm{C}\end{array}$ & $*$ n.a. & [32] \\
\hline $\begin{array}{l}10 \% \\
(5 \mathrm{Ni} 5 \mathrm{Cu}) / \mathrm{CeO}_{2}\end{array}$ & $300-500$ & $\begin{array}{l}5 \text { mol\% } \mathrm{CO}, 25 \\
\text { mol\% } \mathrm{H}_{2} \mathrm{O} \\
\text { balanced in } \mathrm{He}\end{array}$ & $\begin{array}{l}\text { Highest } \mathrm{CO} \\
\text { conversion }(81 \%) \text { achieved } \\
\text { at } 500{ }^{\circ} \mathrm{C}\end{array}$ & $*$ n.a. & [32] \\
\hline $\begin{array}{l}20(w t . \%) C u 2- \\
\text { Ni1/AC }\end{array}$ & $180-350$ & $\begin{array}{l}4.5 \text { vol\% } \mathrm{CO}, 31.1 \\
\mathrm{kPa} \text { steam in } \\
\text { balanced in } \mathrm{N}_{2}\end{array}$ & $\begin{array}{l}\text { Highest } \mathrm{CO} \\
\text { conversion }(70 \%) \text { achieved } \\
\text { at } 350{ }^{\circ} \mathrm{C}\end{array}$ & 4000 & [33] \\
\hline $\begin{array}{l}\text { 20(wt.\%)Cu2- } \\
\text { Ni1/AC }\end{array}$ & $180-350$ & $\begin{array}{l}4.5 \text { vol\% } \mathrm{CO}, 31.1 \\
\mathrm{kPa} \text { steam in } \\
\text { balanced in } \mathrm{N}_{2}\end{array}$ & $\begin{array}{l}\text { Highest } \mathrm{CO} \\
\text { conversion }(54 \%) \text { achieved } \\
\text { at } 350{ }^{\circ} \mathrm{C}\end{array}$ & 4000 & [33] \\
\hline $\begin{array}{l}\mathrm{Cu}-\mathrm{ZnO} / \mathrm{Al}_{2} \mathrm{O}_{3} \\
\text { commercial } \\
\text { catalysts }\end{array}$ & $150-300$ & $\begin{array}{l}4.42 \text { vol\% } \mathrm{CO}, 31.1 \\
\mathrm{kPa} \text { steam in } \\
\text { balanced in } \mathrm{He}\end{array}$ & $\begin{array}{l}\text { Highest conversion }(92 \%) \\
\text { achieved at } 250{ }^{\circ} \mathrm{C}\end{array}$ & 4000 & [34] \\
\hline Pt $(2 w t . \%) / \mathrm{Al}_{2} \mathrm{O}_{3}$ & $180-340$ & $\begin{array}{l}4.5 \text { vol\% } \mathrm{CO}, 31.1 \\
\mathrm{kPa} \text { steam in } \\
\text { balanced in } \mathrm{N}_{2}\end{array}$ & $\begin{array}{l}\text { Highest conversion }(92 \%) \\
\text { achieved at } 310^{\circ} \mathrm{C}\end{array}$ & 4000 & {$[35]$} \\
\hline $\begin{array}{l}\mathrm{Pt}(2 \mathrm{wt} . \%) / \mathrm{CeO}_{2}- \\
\mathrm{Al}_{2} \mathrm{O}_{3}\end{array}$ & $180-340$ & $\begin{array}{l}4.5 \text { vol\% } \mathrm{CO}, 31.1 \\
\mathrm{kPa} \text { steam in } \\
\text { balanced in } \mathrm{N}_{2}\end{array}$ & $\begin{array}{l}\text { Highest conversion }(93 \%) \\
\text { achieved at } 220^{\circ} \mathrm{C}\end{array}$ & 4000 & [35] \\
\hline $\mathrm{Ni} / \mathrm{C}$ & $140-300$ & $\begin{array}{l}1.75 \% \mathrm{CO}, 35.92 \% \\
\mathrm{H}_{2} \mathrm{O}, \text { balanced in } \\
\mathrm{He}\end{array}$ & $\begin{array}{l}\text { Highest conversion }(93 \%) \\
\text { achieved at } 240{ }^{\circ} \mathrm{C}\end{array}$ & 10000 & [5] \\
\hline $\mathrm{Ni}-20 \% \mathrm{CeO}_{2} / \mathrm{C}$ & $140-300$ & $\begin{array}{l}1.75 \% \mathrm{CO}, 35.92 \% \\
\mathrm{H}_{2} \mathrm{O}, \text { balanced in } \\
\mathrm{He}\end{array}$ & $\begin{array}{l}\text { Highest conversion }(93 \%) \\
\text { achieved at } 240^{\circ} \mathrm{C}\end{array}$ & 10000 & {$[5]$} \\
\hline $\mathrm{Cu} / \mathrm{CeAl}$ & $200-400$ & $\begin{array}{l}5 \mathrm{~mol} \% \mathrm{CO}, 25 \\
\text { mol\% } \mathrm{H}_{2} \mathrm{O}, \text { and } \\
\text { balanced in } \mathrm{He}\end{array}$ & $\begin{array}{l}\text { Highest conversion }(95 \%) \\
\text { achieved at } 350{ }^{\circ} \mathrm{C}\end{array}$ & 12000 & This work \\
\hline 1Cu1Ni/CeAl & $200-400$ & $\begin{array}{l}5 \mathrm{~mol} \% \mathrm{CO}, 25 \\
\text { mol\% } \mathrm{H}_{2} \mathrm{O}, \text { and } \\
\text { balanced in } \mathrm{He}\end{array}$ & $\begin{array}{l}\text { Highest conversion }(97 \%) \\
\text { achieved at } 380{ }^{\circ} \mathrm{C}\end{array}$ & 12000 & This work \\
\hline
\end{tabular}

\footnotetext{
$*$ n.a. $=$ not available in the reference.
} 


\section{Editor's comments:}

The first two sentences of the abstract are background/motivation and should be removed. "In this work" restates the obvious and is unnecessary in an abstract, where economy of words is important. Please begin your abstract with "Bimetallic Cu-Ni catalysts were studied..."

Revised as per requested.

The highlights are too long and do not conform to journal requirements (maximum 85 characters each, including spaces). Please rewrite accordingly.

Revised as per requested.

Please have a native English speaking colleague proofread and "polish" your revised manuscript for language and grammar before uploading it. There are many instances of awkward language throughout, e.g., the long, run-on opening sentence: "With the continuous and permanent demand for high-purity hydrogen in the fuel cell technology [1] and in the chemical industry, especially in the ammonia and methanol synthesis processes [2], the water-gas shift reaction is unceasingly under study to improve its applicability since this reaction continues being the key step to transform $\mathrm{CO}$ and $\mathrm{H} 2 \mathrm{O}$ into $\mathrm{CO} 2$ and $\mathrm{H} 2 . "$

Use of English has been revised by a native speaker at the University of Surrey. 
Comparison of mono and bimetallic CU-Ni catalysts for clean $\mathrm{H}_{2}$ production via WGS Analysis of the synergy and anti-synergy behaviour of bimetallic Cu-Ni catalysts $\mathrm{Cu}$ enhanced Ni-based catalysts selectivity to $\mathrm{CO}_{2}$ Monometallic Cu catalyst showed high stability and resistance to start/stop cycles 


\title{
Bimetallic $\mathrm{Cu}-\mathrm{Ni}$ catalysts for the WGS reaction - cooperative or uncooperative effect?
}

\author{
Laura Pastor-Pérez, ${ }^{\mathrm{a}, \mathrm{b}}$ Sai Gu, ${ }^{\mathrm{a}}$ Antonio Sepúlveda-Escribano, ${ }^{\mathrm{b}}$ Tomas R. Reina ${ }^{\mathrm{a}}$ \\ *corresponding author: 1.pastorperez@surrey.ac.uk
}

\begin{abstract}
In this work, bimetallic Cu-Ni catalysts have been studied in the water-gas shift (WGS) reaction, and they have shown different levels of synergy and anti-synergy in terms of catalytic activity and selectivity to the desired products. $\mathrm{Cu}-\mathrm{Ni}$ interactions alter the physicochemical properties of the prepared materials (i.e. surface chemistry, redox behaviour, etc.) and as a result, the catalytic trends are influenced by the catalysts' composition. Our study reveals that $\mathrm{Cu}$ enhances $\mathrm{Ni}$ selectivity to $\mathrm{CO}_{2}$ and $\mathrm{H}_{2}$ by preventing $\mathrm{CO} / \mathrm{CO}_{2}$ methanation, while $\mathrm{Ni}$ does not help to improve $\mathrm{Cu}$ catalytic performance by any means. Indeed, the monometallic $\mathrm{Cu}$ formulation has shown the best results in this study, yielding high levels of reactants conversion and excellent long-term stability. Interestingly, for medium-high temperatures, the bimetallic $1 \mathrm{Cu}-1 \mathrm{Ni}$ outperforms the stability levels reached with the monometallic formulation and becomes an interesting choice even when start-up/shutdowns operations are considered during the catalytic experiments.
\end{abstract}

Keywords: water-gas shift reaction, bimetallic catalysts, $\mathrm{Cu}-\mathrm{Ni}$, synergy, anti-synergy.

\section{Introduction}

In the context of hydrogen fuel processors, the water gas shift reaction has gained a renewed interest given its key role to deliver clean hydrogen streams after the reforming units [1,2]. The exothermic nature of this reaction $(\Delta \mathrm{H}=-41.2 \mathrm{~kJ} / \mathrm{mol})$ makes it thermodynamically favourable at low temperatures but kinetically limited in this temperature window. In order to overcome this drawback, large-scale industrial plants often use a two-step process, comprising one step at $350-400{ }^{\circ} \mathrm{C}$ which is named HTWGS (high-temperature WGS) and employs Fe-Cr-based catalysts, and a second step at lower temperatures, $200-300{ }^{\circ} \mathrm{C}$, which is named LTWGS (low-temperature WGS) and employs $\mathrm{Cu}$ $\mathrm{Zn}$ catalysts [3]. However, such a two steps process is not a viable solution for small applications because of its technical complexity and multiple stages involved. Hence it is very desirable to intensify the process by using only one reaction unit in which the catalyst can operate in a wider temperature range.

The Fe-Cr-based catalyst is the adopted choice for industrial applications in HTWGS reaction [4]. However, the carcinogenic nature and toxicity of chromium, converting this element in the first drawback to solve, have encouraged the catalytic community to find other less harmful alternatives. Ni-based catalysts are being currently investigated as promising systems for the medium-high temperature WGS reaction [5-7]. Excellent levels of $\mathrm{CO}$ conversion can be achieved using $\mathrm{Ni}$ as active phase, but at high temperatures, $\mathrm{CO}$ and $\mathrm{CO}_{2}$ hydrogenation (methanation reactions) appear as undesired processes accounting for an extra hydrogen consumption and, therefore, hampering the implementation of $\mathrm{Ni}$ in realistic applications.

The addition of a second metal such as copper in the catalytic formulation has double-fold beneficial effect: (i) it can suppress the methanation reactions, and (ii) it can improve the overall catalytic activity at lower temperatures. In general, the electronic and geometric perturbations caused by 
bimetallic formulations and alloys in the metals can have an interesting effect on the catalytic activity and selectivity [8]. Specifically, $\mathrm{Ni}-\mathrm{Cu}$ alloys are receiving great interest in different chemical reactions such a WGS [9], steam reforming of ethanol [10], methanol [11], or 1-methylnaphthalene [12], and methane decomposition [13]. Saw et al [9] reported that $\mathrm{Ni}-\mathrm{Cu}$ alloy can enhance $\mathrm{CO}$ adsorption which prevents $\mathrm{CO}$ dissociation and in turn prevents the formation of carbon species during high-temperature WGS reaction. Furthermore, several studies have shown that $\mathrm{Ni}-\mathrm{Cu}$ alloy is able to improve the catalyst's stability and selectivity in ethanol steam reforming $[14,15]$. On the contrary, some controversial results for $\mathrm{Ni}-\mathrm{Cu}$ alloy catalysts have also been reported. For example, the addition of copper to nickel significantly reduced the catalytic activity in styrene hydrogenation and ethane hydrogenolysis to methane [16,17]. The decrease in catalytic activity was explained by changes in the electronic properties of nickel upon the addition of copper, making Ni electron deficient this preventing reactants' activation [18].

This collection of diverse and conflicting results sparks further research on copper-nickel materials. In this work, we have analysed the effect of the bimetallic formulation on the catalytic activity and selectivity (suppression of methanation reaction) during the WGS of a series of $\mathrm{Ni}-\mathrm{Cu}$-based catalysts. The influence of adding $\mathrm{Cu}$ to a $\mathrm{Ni} / \mathrm{CeO}_{2}-\mathrm{Al}_{2} \mathrm{O}_{3}$ catalyst and $\mathrm{Ni}$ to a $\mathrm{Cu} / \mathrm{CeO}_{2}-\mathrm{Al}_{2} \mathrm{O}_{3}$ catalyst, as well as the impact of the $\mathrm{Ni} / \mathrm{Cu}$ ratio are also subject of this study, in which we have also evidenced the relationship between the catalytic activity exhibited by the multi-component materials and their electronic and structural features. Furthermore, we aim to examine whether there are advantages for bimetallic formulations when broad temperature range application is desired.

\section{Experimental}

\subsection{Catalyst preparation}

A $\mathrm{CeO}_{2}-\mathrm{Al}_{2} \mathrm{O}_{3}$ support was prepared via wet impregnation in excess of solvent. The necessary amount of cerium nitrate (Sigma-Aldrich) aiming to obtain $20 \mathrm{wt} . \%$ of $\mathrm{CeO}_{2}$ was impregnated on $\gamma$-alumina powder (Sasol). The impregnation was carried out in $50 \mathrm{~mL}$ of ethanol, evaporated at reduced pressure in a rotary evaporator at $50{ }^{\circ} \mathrm{C}$ till obtaining a dry solid. The support was then filtered, dried and calcined at $500{ }^{\circ} \mathrm{C}$ for $4 \mathrm{~h} . \mathrm{CeO}_{2}-\mathrm{Al}_{2} \mathrm{O}_{3}$ was selected due to their suitability as support for the WGS reaction [19].

Similarly, the catalysts were synthesised by wet impregnation in excess of solvent. The necessary amount of $\mathrm{Ni}$ and $\mathrm{Cu}$ nitrates (Sigma Aldrich) were dissolved in ethanol to obtain a total amount of 15 wt.\% of the active phase. $\mathrm{CeO}_{2}-\mathrm{Al}_{2} \mathrm{O}_{3}$ support was added to the different solutions, with stirring. After $12 \mathrm{~h}$, the excess of solvent was slowly removed under vacuum at $50{ }^{\circ} \mathrm{C}$ and the solids were then dried in the oven overnight at $80^{\circ} \mathrm{C}$. Finally, the dried solids were calcined for $4 \mathrm{~h}$ at $500{ }^{\circ} \mathrm{C}$. In this way, we obtained a series of mono- and bimetallic catalysts with different $\mathrm{Cu}-\mathrm{Ni}$ molar ratios that were labelled as follow: $\mathrm{Ni} / \mathrm{CeAl}, 1 \mathrm{Cu} 2 \mathrm{Ni} / \mathrm{CeAl}, 1 \mathrm{Cu} 1 \mathrm{Ni} / \mathrm{CeAl}, 2 \mathrm{Cu} 1 \mathrm{Ni} / \mathrm{CeAl}$ and $\mathrm{Cu} / \mathrm{CeAl}$.

\subsection{Characterisation}

The textural characterization of the catalysts was carried out by $\mathrm{N}_{2}$ adsorption at $-196{ }^{\circ} \mathrm{C}$ with an AUTOSORB-6 equipment (QUANTACHROME INSTRUMENTS). Samples were previously outgassed at $250{ }^{\circ} \mathrm{C}$ for $4 \mathrm{~h}$.

X-Ray Diffraction (XRD) analysis was undertaken using an X'Pert Pro PANalytical. The diffraction patterns were recorded with $\mathrm{Cu} K \alpha(40 \mathrm{~mA}, 45 \mathrm{kV})$ over a 2 theta range of 5 to $80^{\circ}$, a position sensitive detector using a step size of $0.05^{\circ}$ and a step time of $240 \mathrm{~s}$. The powder XRD patterns were further processed using the accompanying software for the equipment, X'PertHighscore Plus ${ }^{\odot}$. 
The TPR experiments were carried out in a U-shaped quartz cell using a $5 \% \mathrm{H}_{2} / \mathrm{He}$ gas flowing at 50 $\mathrm{mL} \cdot \mathrm{min}^{-1}$, with a heating rate of $10{ }^{\circ} \mathrm{C} \cdot \mathrm{min}^{-1} .50 \mathrm{mg}$ of catalysts were loaded in the quartz reactor that was heated from room temperature to $1000{ }^{\circ} \mathrm{C}$. Hydrogen consumption was followed by on-line mass spectrometry (Pfeiffer, OmniStar GSD 301). CuO standard (99.999\%) was employed for the TPR calibration.

X-ray photoelectron spectroscopy (XPS, K-ALPHA, Thermo Scientific) was used to analyze the samples' surface. All spectra were collected using Al-K radiation $(1486.6 \mathrm{eV})$, monochromatized by a twin crystal monochromator, yielding a focused X-ray spot (elliptical in shape with a major axis length of $400 \mu \mathrm{m}$ ) at $3 \mathrm{~mA} \times 12 \mathrm{kV}$. The alpha hemispherical analyser was operated in the constant energy mode with survey scan pass energies of $200 \mathrm{eV}$ to measure the whole energy band and $50 \mathrm{eV}$ in a narrow scan to selectively measure the particular elements. XPS depth profiles were obtained by sputtering the specimen with a $1 \mathrm{keV} \mathrm{Ar}{ }^{+}$ion beam. XPS data were analysed with Avantage software. A smart background function was used to approximate the experimental backgrounds and surface elemental composition was calculated from background-substracted peak areas. Charge compensation was achieved with the system flood gun that provides low energy electrons and low energy argon ions from a single source. The samples were reduced ex-situ at the reaction temperature $\left(425{ }^{\circ} \mathrm{C}\right)$ and conserved in octane until the analysis.

A simultaneous TG-DTA coupled to a Mass Spectrometer (TG-DTA-MS), was used for the TGA/TPO analysis. The TG-DTA is a TGA/SDTA851and/LF/1600 from METTLER TOLEDO. The Mass Spectrometer is a PFEIFFER VACUUM THERMOSTAR GSD301T quadrupole able to measure a range of mass/charge ratios between 1 and 300 which provides the option of quantitative analysis. The mass spectrometer was calibrated using calcium oxalate standard. Approximately $10 \mathrm{mg}$ of each sample was heated in $100 \mathrm{~mL} / \mathrm{min} \mathrm{O}_{2} / \mathrm{He}$ flows up to $1000{ }^{\circ} \mathrm{C}$ at $10{ }^{\circ} \mathrm{C} / \mathrm{min}$. The desorbed species were identified with the mass spectrometer described above.

\subsection{Catalytic activity}

The catalytic behaviour of the prepared samples covering low and high-temperature water-gas shift reaction was evaluated in a fixed bed flow reactor under atmospheric pressure in the range of temperatures from $200{ }^{\circ} \mathrm{C}$ to $400{ }^{\circ} \mathrm{C}$. Prior to reaction, the catalysts $(0.5 \mathrm{~g})$ were reduced under flowing $\mathrm{H}_{2}\left(50 \mathrm{~mL} \cdot \mathrm{min}^{-1}\right)$ for $1 \mathrm{~h}$ at $400{ }^{\circ} \mathrm{C}$. For the catalytic screening, a model mixture comprised of $25 \%$ vol. $\mathrm{H}_{2} \mathrm{O}+5 \%$ vol. $\mathrm{CO}$ was utilised. A post reforming surrogate stream was also utilised consisting of $25 \%$ vol. $\mathrm{H}_{2} \mathrm{O}+8 \%$ vol. $\mathrm{CO}, 37 \% \mathrm{H}_{2}$ and $8 \% \mathrm{CO}_{2}$. For all the WGS runs the gas hourly space velocity (GHSV) was $12000 \mathrm{~h}^{-1}$.

\section{Results and discussion}

3.1 Catalysis characterization

Table 1. Textural properties of supports and catalysts.

\begin{tabular}{lccc}
\hline Samples & BET $\left(\mathbf{m}^{2} / \mathbf{g}\right)$ & Total Pore Volume $\left(\mathbf{c m}^{3} / \mathbf{g}\right)$ & Pore Size $(\mathbf{n m})$ \\
\hline $\mathrm{Al}_{2} \mathrm{O}_{3}$ & 216 & 0.513 & 6.15 \\
$\mathrm{CeO}_{2}-\mathrm{Al}_{2} \mathrm{O}_{3}$ & 159 & 0.361 & 6.14 \\
$\mathrm{Ni} / \mathrm{CeAl}$ & 141 & 0.308 & 6.14 \\
$1 \mathrm{Cu} 2 \mathrm{Ni} / \mathrm{CeAl}$ & 139 & 0.300 & 6.12 \\
$1 \mathrm{Cu} 1 \mathrm{Ni} / \mathrm{CeAl}$ & 138 & 0.306 & 6.12 \\
$2 \mathrm{Cu} 1 \mathrm{Ni} / \mathrm{CeAl}$ & 134 & 0.302 & 6.03 \\
\hline
\end{tabular}


Table 1 provides the textural properties of the bare $\mathrm{Al}_{2} \mathrm{O}_{3}, \mathrm{CeO}_{2}-\mathrm{Al}_{2} \mathrm{O}_{3}$ supports and all the synthesised catalysts. Both supports and their corresponding $\mathrm{Ni}, \mathrm{Ni}-\mathrm{Cu}$ and $\mathrm{Cu}$ catalysts exhibit type IV isotherms (not shown), typically ascribed to mesoporous materials according to IUPAC classifications. The surface areas of the prepared materials ranged from $115-216 \mathrm{~m}^{2} \mathrm{~g}^{-1}$ while the primary pore diameters estimated from the maximum in the BJH pore size distribution are around 6 $\mathrm{nm}$. The textural properties are governed by the primary $\gamma$-alumina support. The expected decrease in surface area and pore volume after metal and oxide introduction is related to partial blockage of pores of the $\mathrm{Al}_{2} \mathrm{O}_{3}$ support and dilution effect due to the high metal loading. Overall changes on the textural properties within the studied series are not remarkable and in principle, we do not expect an impact of the textural features on the catalytic performance.

Figure $1 \mathrm{~A}$ shows the $\mathrm{X}$-Ray diffraction patterns of the calcined catalysts and the bare $\mathrm{CeO}_{2}-\mathrm{Al}_{2} \mathrm{O}_{3}$ support. All the samples present the typical diffraction peaks of the ceria fluorite cubic structure (JCPDS\# 00-004-0593) and those of the primary $\gamma-\mathrm{Al}_{2} \mathrm{O}_{3}$ support (JCPDS\# 00-048-0367). As for the $\mathrm{Cu}$-containing samples, some peaks related to monoclinic CuO (JCPDS\# 80-1917) were detected in the monometallic $\mathrm{Cu} / \mathrm{CeAl}$ sample and also in the bimetallic $2 \mathrm{Cu} 1 \mathrm{Ni} / \mathrm{CeAl}$ (small peaks). As for the $\mathrm{Ni}$-containing samples, no reflections related to $\mathrm{NiO}$ species were detected. This lack of $\mathrm{NiO}$ peaks indicates the good dispersion and small particle size of Ni species in the prepared materials.

Figure 1B presents the diffraction patterns of the samples after a $1 \mathrm{~h}$ of reduction treatment emulating the pre-activation step before every WGS run. Some interesting remarks are extracted from these data. First, the pre-activation in hydrogen does not produce any sintering neither on $\mathrm{CeO}_{2}$ nor on $\mathrm{Ni}$ species, a fact that will help to achieve good performance in the shift reaction. Also, the reduction of $\mathrm{CuO}$ to $\mathrm{Cu}^{0}$ is evidenced for the $\mathrm{Cu} / \mathrm{CeAl}$ and the $2 \mathrm{Cu} 1 \mathrm{Ni} / \mathrm{CeAl}$ samples, with peaks at $2 \theta=43.3^{\circ}$ and $50.4^{\circ}$ attributed to metallic copper (JCPDS\# 4-0836). Zooming into the 2theta region between $40^{\circ}-54^{\circ}$ (Fig 1C), a small shift of the metallic $\mathrm{Cu}$ phase can be observed in the $2 \mathrm{Cu} 1 \mathrm{Ni} / \mathrm{CeAl}$ sample, showing a diffraction peak shifted at intermediate positions between those for pure $\mathrm{Cu}$ and $\mathrm{Ni}$ thus indicating the formation of $\mathrm{Cu}-\mathrm{Ni}$ alloy [7]. Since in the rest of the samples no peaks for $\mathrm{Ni}$ and $\mathrm{Cu}$ were detected, the presence of the alloy should not be discarded. It is noteworthy that at high nickel concentrations a homogeneous solid solution of copper and nickel can be formed, whereas as the $\mathrm{Ni} / \mathrm{Cu}$ ratio approaches 1 , copper has a tendency to be segregated in order to minimize the interface surface energy $[20,18]$. 

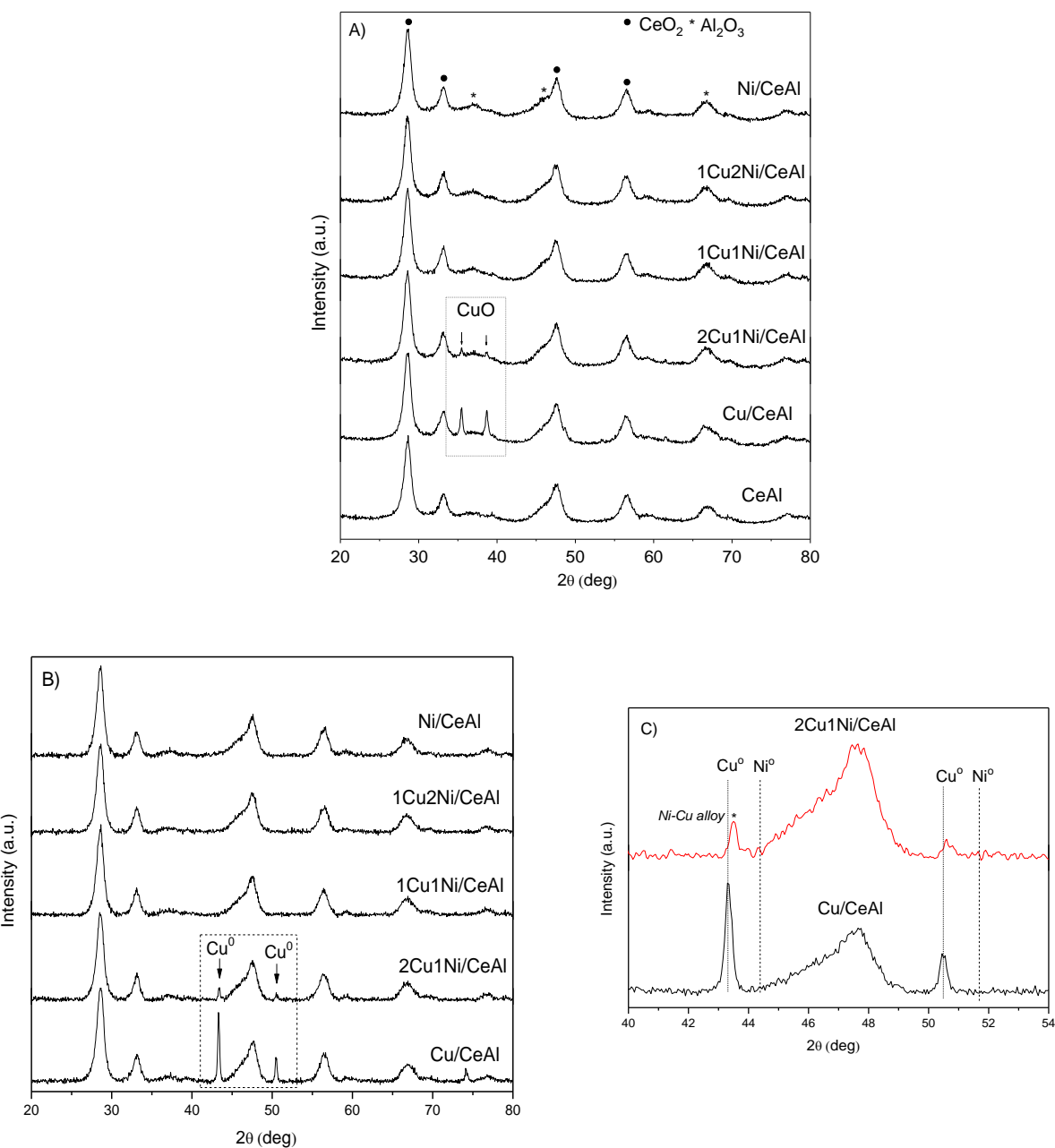

Figure 1. XRD of A) calcined samples, B) reduced samples and, C) $40^{\circ}-54^{\circ}$ region of the XRD patterns of reduced samples.

The redox properties and the metal-support interactions were studied by means of $\mathrm{H}_{2}$-TPR as depicted in Figure 2. The TPR profiles and the total reducibility percentages $(\mathrm{R}(\%))$ reveal substantially different redox properties among the studied materials. More precisely, the TPR profile (Figure 2 (a)) of the $\mathrm{Ni} / \mathrm{CeAl}$ sample is governed by two broad reduction zones, a low temperature one ca 200-400 ${ }^{\circ} \mathrm{C}$ and a high-temperature reduction event between 450 and $850{ }^{\circ} \mathrm{C}$, with a shoulder at $900{ }^{\circ} \mathrm{C}$. The first reduction zone is related to the reduction $\mathrm{Ni}^{2+}$ to metallic $\mathrm{Ni}$ for the small $\mathrm{Ni}$ particles, accompanied by the reduction of surface ceria. It is seen that $\mathrm{CeO}_{2}$ loading shifts the nickel reduction to lower temperature values, indicating some changes in the catalyst's properties promoted by $\mathrm{CeO}_{2}$ as reported elsewhere [21,22]. The second reduction zone is ascribed to $\mathrm{NiO}$ particles with a strong support influence and also to the ceria bulk reduction [23]. The shoulder at high temperature has been previously attributed to the reduction of $\mathrm{CeAlO}_{3}[24,22]$, although this phase has not been identified by XRD. 


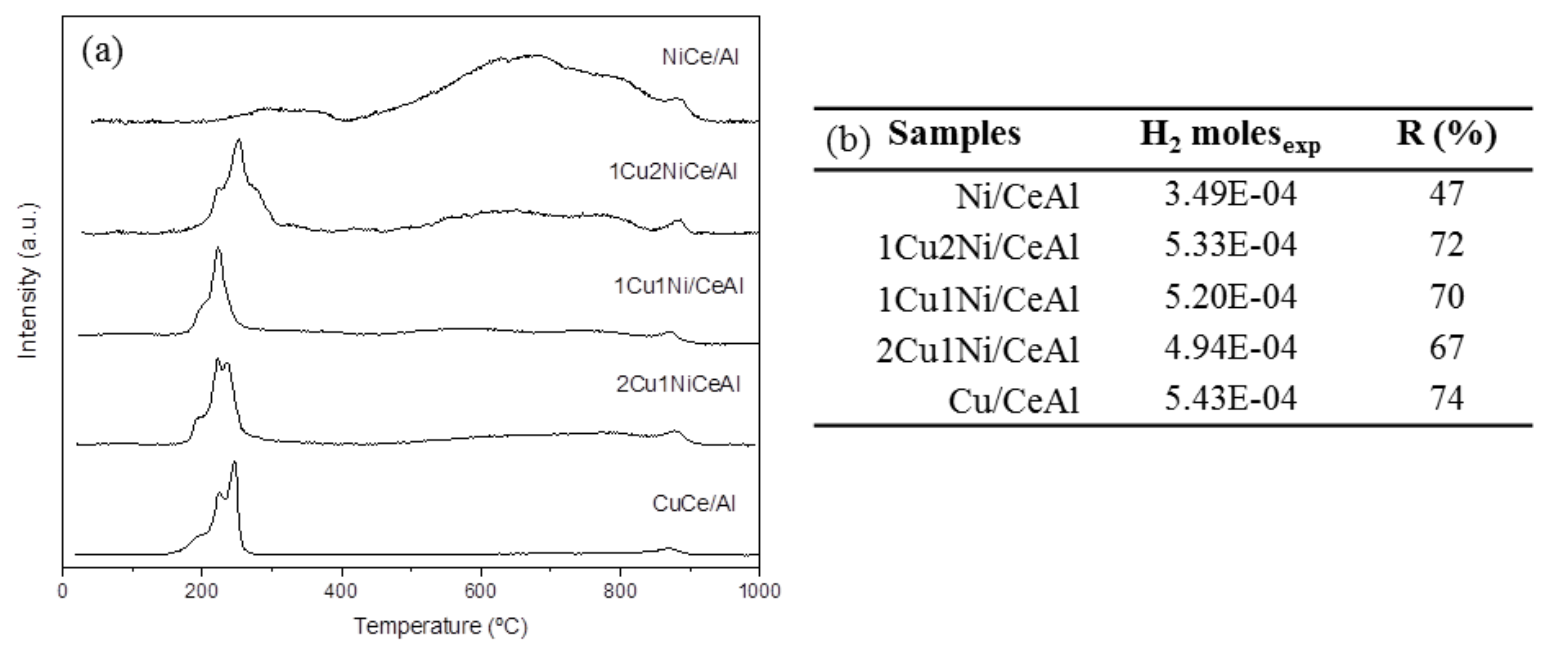

Figure 2. (a) $\mathrm{H}_{2}$-TPR profiles and (b) $\mathrm{H}_{2}$ experimental moles consumed and overall reducibility of the studied samples.

The reduction profile of the other monometallic catalyst, $\mathrm{Cu} / \mathrm{CeAl}$, was characterised by one reduction zone containing several peaks between 160 and $280{ }^{\circ} \mathrm{C}$. It is widely accepted that the shoulder at lower temperatures represents the reduction of $\mathrm{CuO}$ nanoparticles highly dispersed on the $\mathrm{CeAl}$ support, while the two peaks at higher temperatures represent the reduction of bulk $\mathrm{CuO}$ particles and surface $\mathrm{CeO}_{2}$ interacting to different extent $[25,26]$. Furthermore, for the bimetallic catalysts, the addition of $\mathrm{Cu}$ to the Ni-containing samples shifts the reduction events towards lower temperatures. The TPR profiles of the bimetallic samples show that the presence of $\mathrm{Cu}$ as a second metal lowered the reduction temperature of $\mathrm{Ni}$ as was previously shown. Very likely, $\mathrm{Cu}$ disrupts the strong Ni$\mathrm{Al}_{2} \mathrm{O}_{3}$ interaction and changes the situation in such a way that for the bimetallic systems $\mathrm{NiO}_{\mathrm{x}}-\mathrm{CuO}_{\mathrm{x}}$ particles are in intimate contact and present weaker metal-support interaction. The latter explains the easier reduction of $\mathrm{NiO}_{x}$ particles in the presence of $\mathrm{CuO}_{x}$ [27,28]. Irrespectively of the mechanism, the improvement of reducibility of $\mathrm{NiO}$ when $\mathrm{CuO}$ is added mirrors a synergistic interaction between the metal oxide phases that not only alters their redox properties but also explains the decrease of their crystallite size observed by XRD. Indeed, a more homogeneous peak (presence of only one peak at higher temperatures) was observed for the $1 \mathrm{Cu} 1 \mathrm{Ni}$ composition, suggesting a much stronger interaction between $\mathrm{CuO}$ and $\mathrm{NiO}$ [7]. This observation is also corroborated when the total reducibility, $\mathrm{R}(\%)$ is calculated. As shown in Figure 2 (b), the addition of $\mathrm{Cu}$ to $\mathrm{Ni} / \mathrm{CeAl}$ sample increases notoriously the reducibility of the sample, being substantially boosted for the $1 \mathrm{Cu} 2 \mathrm{Ni} / \mathrm{CeAl}$ and $1 \mathrm{Cu} 1 \mathrm{Ni} / \mathrm{CeAl}$ samples. However, for copper-rich bimetallic compositions $(\mathrm{Cu}>\mathrm{Ni})$, the reducibility slightly decreases, due to the copper segregation happening for this sample as discussed and corroborated in the XPS section. In any case, there is a clear impact of the $\mathrm{Ni}-\mathrm{Cu}$ contact on the redox properties of the samples.

The XPS studies revealed the chemical state of nickel and copper upon reduction, as well as changes in the electronic properties of nickel in the presence of copper and aluminium species. 


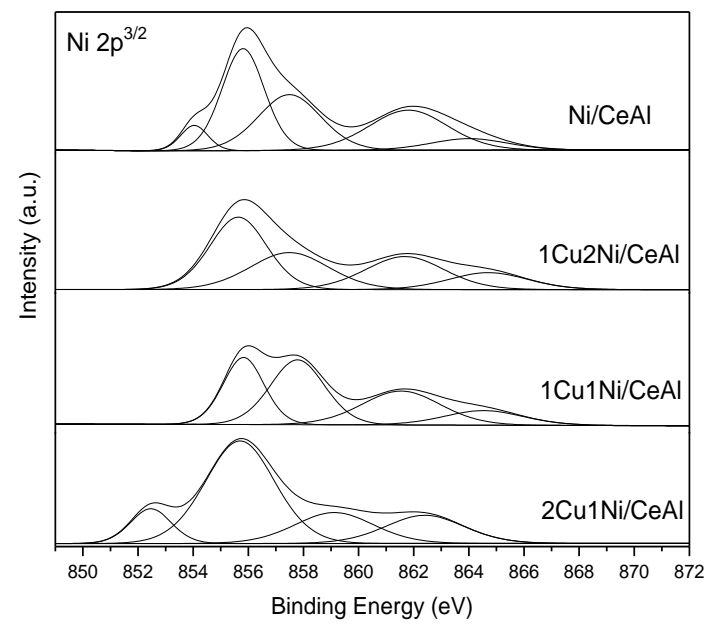

Figure 3. XPS core level of the Ni $2 \mathrm{p}_{3 / 2}$ region for catalysts reduced at $450{ }^{\circ} \mathrm{C}$.

The Ni $2 p_{3 / 2}$ spectra for all samples reduced at $450{ }^{\circ} \mathrm{C}$ (Figure 3 ) are characterised by a main peak corresponding to the final state $2 p^{5} 3 d^{9} \mathrm{~L}$ (L means a ligand hole) and a satellite at higher binding energy (B.E.) corresponding to $2 p^{5} 3 d^{8}$ L. Furthermore, Figure 3 shows the curve fitting of the experimental spectra and the B.E. values obtained from these curves are compiled in Table 2.

Table 2. Binding energies of the $\mathrm{Ni} 2 p_{3 / 2}$ and $\mathrm{Cu} 2 p_{3 / 2}$ levels in the catalysts reduced at $450{ }^{\circ} \mathrm{C}$.

\begin{tabular}{|c|c|c|}
\hline Samples & Ni $2 p_{3 / 2}$ & $\mathrm{Cu} \mathrm{2p_{3/2 }}$ \\
\hline $\mathrm{Ni} / \mathrm{CeAl}$ & $854.0-855.8-857.5$ & - \\
\hline $1 \mathrm{Cu} 2 \mathrm{Ni} / \mathrm{CeAl}$ & $855.6-857.5$ & $931.2-933.1-935.2$ \\
\hline $1 \mathrm{Cu} 1 \mathrm{Ni} / \mathrm{Ce} \mathrm{Al}$ & $855.8-857.8$ & 931.9 - $933.9-936.2$ \\
\hline $2 \mathrm{Cu} 1 \mathrm{Ni} / \mathrm{CeAl}$ & $852.5-855.7$ & 931.9 - 933.4- 935.3 \\
\hline $\mathrm{Cu} / \mathrm{CeAl}$ & -- & $932.1-933.8-935.4$ \\
\hline
\end{tabular}

For the $\mathrm{Ni} / \mathrm{CeAl}$ sample, a small peak appears at $854.0 \mathrm{eV}$ which is attributed to metallic Ni. This high B.E. value and the small amount of reduced $\mathrm{Ni}$ obtained are due to the presence $\mathrm{Ni}$ atoms surrounded by $\mathrm{Al}^{3+}$ or $\mathrm{Ce}^{4+}$ (through $\mathrm{O}^{2-}$ linkage) as the second neighbours, causing strong $\mathrm{Ni}-\mathrm{Al}$ or $\mathrm{Ni}-\mathrm{Ce}$ interactions. The following two peaks, at around 855.8 and $857.5 \mathrm{eV}$ are assigned to $\mathrm{Ni}^{2+}$ species.

Regarding the bimetallic Cu-Ni samples, it can be seen that the Ni spectra shape changed and the B.E. are shifted to higher values as the amount of copper increases (see Table 2), this suggesting that nickel is at different oxidation states in these samples. As previously reported elsewhere, an increase in the B.E. of the main Ni peak was observed in Ni-Pd alloys $[29,30]$, which has been related to the reduction in $\mathrm{Ni} d$ hole density, namely, a charge transfer to adjacent electronegative $\mathrm{Pd}$ atoms from $\mathrm{Ni}$. In the case of this study, the increase in the binding energies for $\mathrm{Ni}$ also can be related to changes in the $\mathrm{Ni} d$-band arising from the charge transfer from $\mathrm{Ni}$ to the adjacent $\mathrm{Cu}$ atoms. However, at higher copper amounts $(\mathrm{Cu}>\mathrm{Ni})$, the B.E. value tends to restore to those values corresponding to metallic Ni $(852.5 \mathrm{eV})$ due to copper segregation. This behaviour was also confirmed by the XRD results obtained for the $2 \mathrm{Cu} 1 \mathrm{Ni} / \mathrm{CeAl}$ catalyst. 
The $\mathrm{Cu}$ monometallic catalyst exhibits the main peaks at around 932.1 and $933.8 \mathrm{eV}$, and a satellite peak at higher binding energies (Figure 4). According to the literature data, metallic $\mathrm{Cu}$ and $\mathrm{Cu}_{2} \mathrm{O}$ are characterized by the $\mathrm{Cu} 2 p_{3 / 2}$ binding energy in the range of $932.4-932.8 \mathrm{eV}$, while the binding energy for $\mathrm{CuO}$ is between 933.6 and $934.6 \mathrm{eV}$ [5]. In contrast, a continuous decline in the binding energy with the increase of the amount of $\mathrm{Ni}$ relative to metallic $\mathrm{Cu}$ and $\mathrm{Cu}_{2} \mathrm{O}$ is observed for the reduced bimetallic $\mathrm{Ni}-\mathrm{Cu}$ catalysts. This fact is in agreement with a charge transfer from $\mathrm{Ni}$ to the adjacent $\mathrm{Cu}$, matching well with the Ni XPS profiles discussed above.

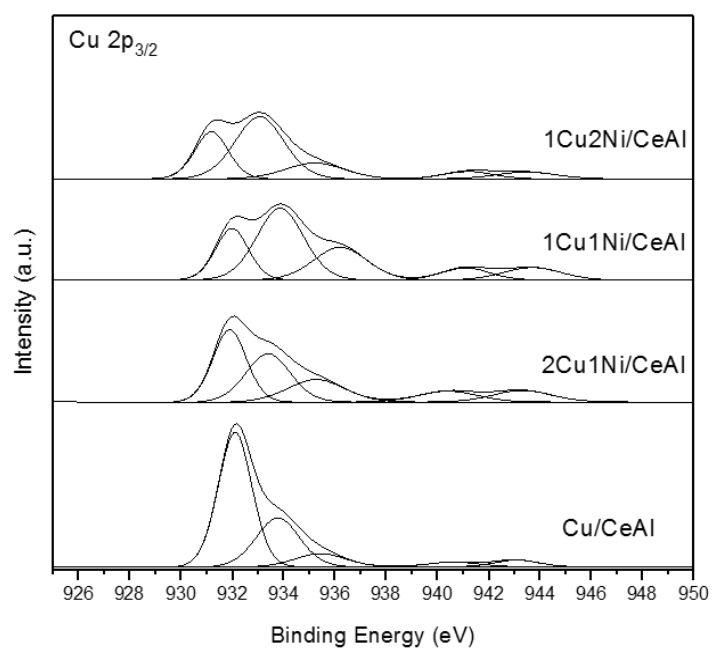

Figure 4. XPS $\mathrm{Cu} 2 \mathrm{p}_{3 / 2}$ spectra for all $\mathrm{Cu}$-containing samples reduced at $450{ }^{\circ} \mathrm{C}$.

\subsection{Catalytic behaviour}

In a first screening, the catalytic behaviour of the monometallic and bimetallic samples was determined at 200-400 ${ }^{\circ} \mathrm{C}$ in a model mixture comprised of $25 \%$ vol. $\mathrm{H}_{2} \mathrm{O}+5 \%$ vol. $\mathrm{CO}$ at a relatively high space velocity $\left(12000 \mathrm{~h}^{-1}\right)$. Figure 5 shows the $\mathrm{CO}$ conversion in the WGS reaction as a function of temperature for all samples. As shown in the Figure, the monometallic $\mathrm{Cu}$-based catalyst is the best system within the studied series, exhibiting high levels of $\mathrm{CO}$ conversion even in the hightemperature range. This result corroborates the suitability of $\mathrm{Cu}$ as an active phase for WGS and the advanced behaviour of $\mathrm{Cu}-\mathrm{CeO}_{2}-\mathrm{Al}_{2} \mathrm{O}_{3}$ mixtures to overcome the space velocity restrictions of the WGS reaction, as recently demonstrated [31]. 


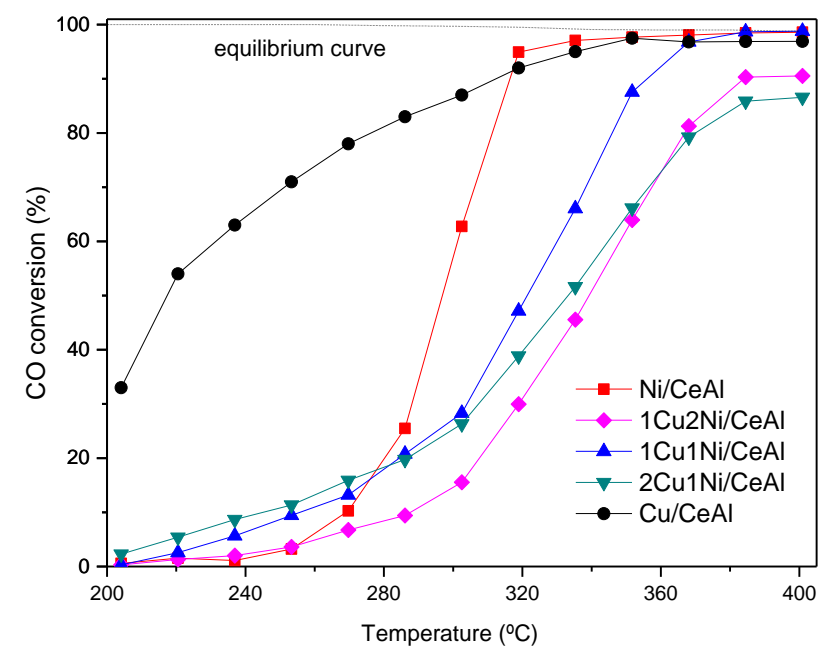

Figure 5. CO conversion as a function of temperature for all samples.

Interestingly, different sort of scenarios are found for the bimetallic and the monometallic $\mathrm{Ni}$ catalysts. Indeed, they all have a much more delayed light-off and only the monotallic $\mathrm{Ni}$ and the $1 \mathrm{Cu} 1 \mathrm{Ni}$ systems reached equilibrium conversions. It has to be mentioned that the monometallic $\mathrm{Ni}$ catalyst favoured the formation of $\mathrm{CH}_{4}$ consuming hydrogen (starting the hydrogenation at $280{ }^{\circ} \mathrm{C}$ with $1 \%$ of methane and reaching a $5 \%$ at $320{ }^{\circ} \mathrm{C}$ ). This trend was previously observed [4] and actually reflects the disadvantage of $\mathrm{Ni}$ versus $\mathrm{Cu}$ to favour parallel reactions. A strategy to suppress methanation for Ni-based catalysts is to incorporate small amounts of $\mathrm{Cu}$ and to form the $\mathrm{Cu}-\mathrm{Ni}$ alloy that suppresses the hydrogenation activity during the reaction [9]. For the rest of the samples (bimetallic $\mathrm{Cu}-\mathrm{Ni}$ and monometallic $\mathrm{Cu}$ ) no methane formation was detected. In particular, our $1 \mathrm{Cu} 1 \mathrm{Ni} / \mathrm{CeAl}$ catalyst presented the highest levels of $\mathrm{CO}$ conversion and did not produce methane in the whole studied temperature range. In fact, this catalyst was the only one in which the $\mathrm{Cu}-\mathrm{Ni}$ alloy was detected by XRD and also was the system with the stronger modification of Ni electronic features according to the XPS analysis. Therefore, the physicochemical characterisation matches with the observed catalytic behaviour and points out the suitability of the $\mathrm{Cu}-\mathrm{Ni}$ alloy to improve the performance of monometallic Ni-based catalysts for the shift reaction. On the contrary, the extreme compositions $2 \mathrm{Cu}-1 \mathrm{Ni}$ and $1 \mathrm{Cu}-2 \mathrm{Ni}$ did not contribute to improving the overall activity of the multicomponent catalysts. This observation reflects the need to carefully optimise the chemical composition of bimetallic catalysts to actually obtain some benefits from the mixed active phases, otherwise, the bi-metallic strategy could result detrimental as reflected in this study.

Table 3. Comparison with state of art materials published in the literature.

\begin{tabular}{|c|c|c|c|c|c|}
\hline Catalyst & Temp. range & Gas mixture & CO conversion & GHSV $\left(h^{-1}\right)$ & Reference \\
\hline $\begin{array}{l}10 \%- \\
(5 \mathrm{Cu} 5 \mathrm{Ni}) @ \mathrm{CeO}_{2} \\
\text { (shell catalyst) }\end{array}$ & $300-500$ & $\begin{array}{l}5 \text { mol\% } \mathrm{CO}, 25 \\
\text { mol\% } \mathrm{H}_{2} \mathrm{O} \\
\text { balanced in } \mathrm{He}\end{array}$ & $\begin{array}{l}\text { Highest } \mathrm{CO} \\
\text { conversion }(92 \%) \text { achieved } \\
\text { at } 500{ }^{\circ} \mathrm{C}\end{array}$ & $*$ n.a. & [32] \\
\hline $\begin{array}{l}10 \% \\
(5 \mathrm{Ni} 5 \mathrm{Cu}) / \mathrm{CeO}_{2}\end{array}$ & $300-500$ & $\begin{array}{l}5 \text { mol\% } \mathrm{CO}, 25 \\
\text { mol\% } \mathrm{H}_{2} \mathrm{O} \\
\text { balanced in } \mathrm{He}\end{array}$ & $\begin{array}{l}\text { Highest } \mathrm{CO} \\
\text { conversion }(81 \%) \text { achieved } \\
\text { at } 500{ }^{\circ} \mathrm{C}\end{array}$ & $*$ n.a. & [32] \\
\hline $\begin{array}{l}\text { 20(wt.\%)Cu2- } \\
\text { Ni1/AC }\end{array}$ & $180-350$ & $\begin{array}{l}4.5 \text { vol\% } \mathrm{CO}, 31.1 \\
\mathrm{kPa} \text { steam in } \\
\text { balanced in } \mathrm{N}_{2}\end{array}$ & $\begin{array}{l}\text { Highest } \mathrm{CO} \\
\text { conversion }(70 \%) \text { achieved } \\
\text { at } 350{ }^{\circ} \mathrm{C}\end{array}$ & 4000 & [33] \\
\hline
\end{tabular}




\begin{tabular}{|c|c|c|c|c|c|}
\hline $\begin{array}{l}20(w t . \%) C u 2- \\
\text { Ni1/AC }\end{array}$ & $180-350$ & $\begin{array}{l}4.5 \text { vol\% } \mathrm{CO}, 31.1 \\
\mathrm{kPa} \text { steam in } \\
\text { balanced in } \mathrm{N}_{2}\end{array}$ & $\begin{array}{l}\text { Highest } \mathrm{CO} \\
\text { conversion }(54 \%) \text { achieved } \\
\text { at } 3500^{\circ} \mathrm{C}\end{array}$ & 4000 & [33] \\
\hline $\begin{array}{l}\mathrm{Cu}-\mathrm{ZnO} / \mathrm{Al}_{2} \mathrm{O}_{3} \\
\text { commercial } \\
\text { catalysts }\end{array}$ & $150-300$ & $\begin{array}{l}4.42 \text { vol\% CO, } 31.1 \\
\mathrm{kPa} \text { steam in } \\
\text { balanced in } \mathrm{He}\end{array}$ & $\begin{array}{l}\text { Highest conversion }(92 \%) \\
\text { achieved at } 2500^{\circ} \mathrm{C}\end{array}$ & 4000 & [34] \\
\hline $\mathrm{Pt}(2 \mathrm{wt} . \%) / \mathrm{Al}_{2} \mathrm{O}_{3}$ & $180-340$ & $\begin{array}{l}4.5 \text { vol\% } \mathrm{CO}, 31.1 \\
\mathrm{kPa} \text { steam in } \\
\text { balanced in } \mathrm{N}_{2}\end{array}$ & $\begin{array}{l}\text { Highest conversion (92\%) } \\
\text { achieved at } 310^{\circ} \mathrm{C}\end{array}$ & 4000 & [35] \\
\hline $\begin{array}{l}\mathrm{Pt}(2 \mathrm{wt} . \%) / \mathrm{CeO}_{2^{-}} \\
\mathrm{Al}_{2} \mathrm{O}_{3}\end{array}$ & $180-340$ & $\begin{array}{l}4.5 \text { vol\% } \mathrm{CO}, 31.1 \\
\mathrm{kPa} \text { steam in } \\
\text { balanced in } \mathrm{N}_{2}\end{array}$ & $\begin{array}{l}\text { Highest conversion }(93 \%) \\
\text { achieved at } 220^{\circ} \mathrm{C}\end{array}$ & 4000 & [35] \\
\hline $\mathrm{Ni} / \mathrm{C}$ & $140-300$ & $\begin{array}{l}1.75 \% \mathrm{CO}, 35.92 \% \\
\mathrm{H}_{2} \mathrm{O} \text {, balanced in } \\
\mathrm{He}\end{array}$ & $\begin{array}{l}\text { Highest conversion (93\%) } \\
\text { achieved at } 240{ }^{\circ} \mathrm{C}\end{array}$ & 10000 & [5] \\
\hline $\mathrm{Ni}-20 \% \mathrm{CeO}_{2} / \mathrm{C}$ & $140-300$ & $\begin{array}{l}1.75 \% \mathrm{CO}, 35.92 \% \\
\mathrm{H}_{2} \mathrm{O} \text {, balanced in } \\
\mathrm{He}\end{array}$ & $\begin{array}{l}\text { Highest conversion (93\%) } \\
\text { achieved at } 2400^{\circ} \mathrm{C}\end{array}$ & 10000 & [5] \\
\hline $\mathrm{Cu} / \mathrm{CeAl}$ & $200-400$ & $\begin{array}{l}5 \mathrm{~mol} \% \mathrm{CO}, 25 \\
\text { mol } \% \mathrm{H}_{2} \mathrm{O} \text {, and } \\
\text { balanced in } \mathrm{He}\end{array}$ & $\begin{array}{l}\text { Highest conversion (95\%) } \\
\text { achieved at } 350^{\circ} \mathrm{C}\end{array}$ & 12000 & This work \\
\hline $1 \mathrm{Cu} 1 \mathrm{Ni} / \mathrm{CeAl}$ & $200-400$ & $\begin{array}{l}5 \mathrm{~mol} \% \mathrm{CO}, 25 \\
\text { mol\% } \mathrm{H}_{2} \mathrm{O} \text {, and } \\
\text { balanced in } \mathrm{He}\end{array}$ & $\begin{array}{l}\text { Highest conversion }(97 \%) \\
\text { achieved at } 380^{\circ} \mathrm{C}\end{array}$ & 12000 & This work \\
\hline
\end{tabular}

For sake of comparison with the state of the art catalysts, Table 3 showcases the maximum CO conversion levels of selected reference catalysts including, bimetallic $\mathrm{Ni}-\mathrm{Cu}$, commercial $\mathrm{Cu}-$ $\mathrm{ZnO} / \mathrm{Al}_{2} \mathrm{O}_{3}$ and noble metal-based catalysts. It should be stated that such a comparison is not always straightforward given the multiple reaction conditions employed in available works in literature. Herein we have selected those works that employed similar reaction conditions as those used in this study. As shown in the table the catalysts presented in this study can be ranked as high performing catalysts for the medium temperature shift reaction. Clearly, benchmark catalysts and noble metal based system outperform our materials in the low-temperature range, however, our mono and bimetallic catalysts are very efficient for temperatures above $300{ }^{\circ} \mathrm{C}$ and clearly more efficient than reference bimetallic $\mathrm{Cu}-\mathrm{Ni}$ systems reported in the literature. In addition, the catalysts presented in this study performed at relatively high space velocities which may result beneficial to design compact reactors for portable applications.

In the context of the WGS reaction for hydrogen purification goals, the WGS unit is typically linked to the reformer outlet. Therefore, the influence of post reforming mixtures must be tested for the potential implementation of the developed catalysts in a WGS unit for portable applications. Figure 6 shows the results of the WGS tests under post reforming conditions for selected catalysts. 


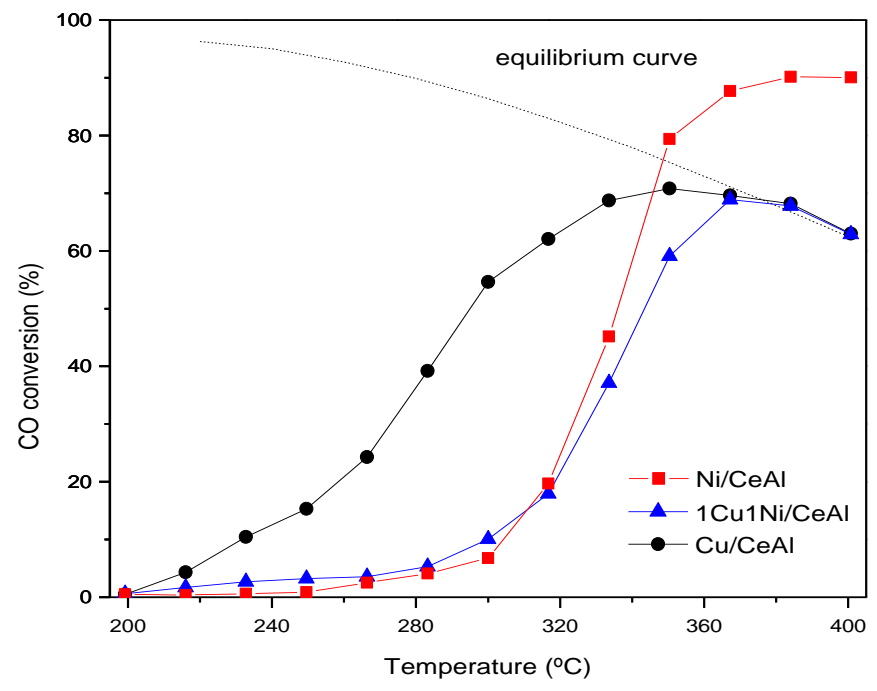

Figure 6. $\mathrm{CO}$ conversion as a function of temperature using a post-reforming mixture $\left(25 \%\right.$ vol. $\mathrm{H}_{2} \mathrm{O}$ $+8 \%$ vol. $\mathrm{CO}, 37 \% \mathrm{H}_{2}$ and $8 \% \mathrm{CO}_{2}$ )

As a general trend, the $\mathrm{CO}$ conversion is shifted towards higher temperatures as a consequence of Le Chatelier principle. Furthermore, this test corroborates the superiority of monometallic $\mathrm{Cu}$ in comparison with monometallic $\mathrm{Ni}$ and bimetallic $1 \mathrm{Cu}-1 \mathrm{Ni}$. Interestingly, the monometallic $\mathrm{Ni}$ overpassed the equilibrium conversion. This is actually an immediate reflect of the methanation reaction providing an alternative route for $\mathrm{CO}$ elimination. Such undesirable competitive reaction was enhanced under post-reforming conditions and discards the use of monometallic Ni as suitable WGS catalysts for a wide temperature range applications. The bimetallic catalysts composed by the $1 \mathrm{Cu}-$ $1 \mathrm{Ni}$ alloy still presented intermediate catalytic activity, reaching equilibrium conversion at $350{ }^{\circ} \mathrm{C}$ with no sign of methanation. It seems obvious that the bimetallic strategy works if we are aiming to improve the catalytic performance of a Ni-based catalyst; however, the bimetallic approach will worsen the behaviour of a $\mathrm{Cu}$ monometallic catalyst. As mentioned in the Introduction section, a Nibased material could be more suitable for the medium-high temperature range since the $\mathrm{Cu}$ nanoparticles could sinter. Under these particular conditions, it is then desirable to design a bimetallic catalyst ideally with a well-defined $\mathrm{Cu}-\mathrm{Ni}$ alloy. Nevertheless, if the target is the low-temperature shift reaction the use of mixed $\mathrm{Cu}-\mathrm{Ni}$ systems does not bring any advantage, and the monometallic $\mathrm{Cu}$ system must be the catalyst of choice. The catalyst selection will be therefore a non-trivial question since, depending on the fuel processor configuration (reforming - shift unit - CO-PrOx - fuel cell) [36], the heat integration may favour the selection of a medium temperature shift catalyst where monometallic copper will still be the obvious choice. For higher temperatures, the bimetallic $1 \mathrm{Cu}-1 \mathrm{Ni}$ could be an interesting choice, given the well-known tendency of monometallic copper for sintering at temperatures beyond $500{ }^{\circ} \mathrm{C}$.

In this study we have focused on the medium-temperature shift reaction and, aiming to test further the robustness of our best catalyst in the whole range of temperature, the monometallic $\mathrm{Cu}$ system was submitted to a long-term stability run including some start/stop cycles. The start/stop experiments replicate the start-up/shut-downs operations of a portable device (i.e. a hydrogen-powered vehicle) and they constitute a key test to identify efficient WGS catalysts for realistic applications. As shown in Figure 7 the activity of the catalyst was rather stable and only a drop from 58 to $48 \%$ was observed after more than $230 \mathrm{~h}$ of continuous operation with 5 series of start/stop cycles in between. This result is highly commendable especially if we consider that during the stop stages the feed kept passing through the catalytic bed (at room temperature), thus provoking the condensation of water on the catalyst's pores and potentially damaging the activity. The capacity of this catalyst to successfully 
withstand start-up/shut down operations is a great achievement and makes this material a promising catalyst to be further studied for its implementation in hydrogen fuel processors.

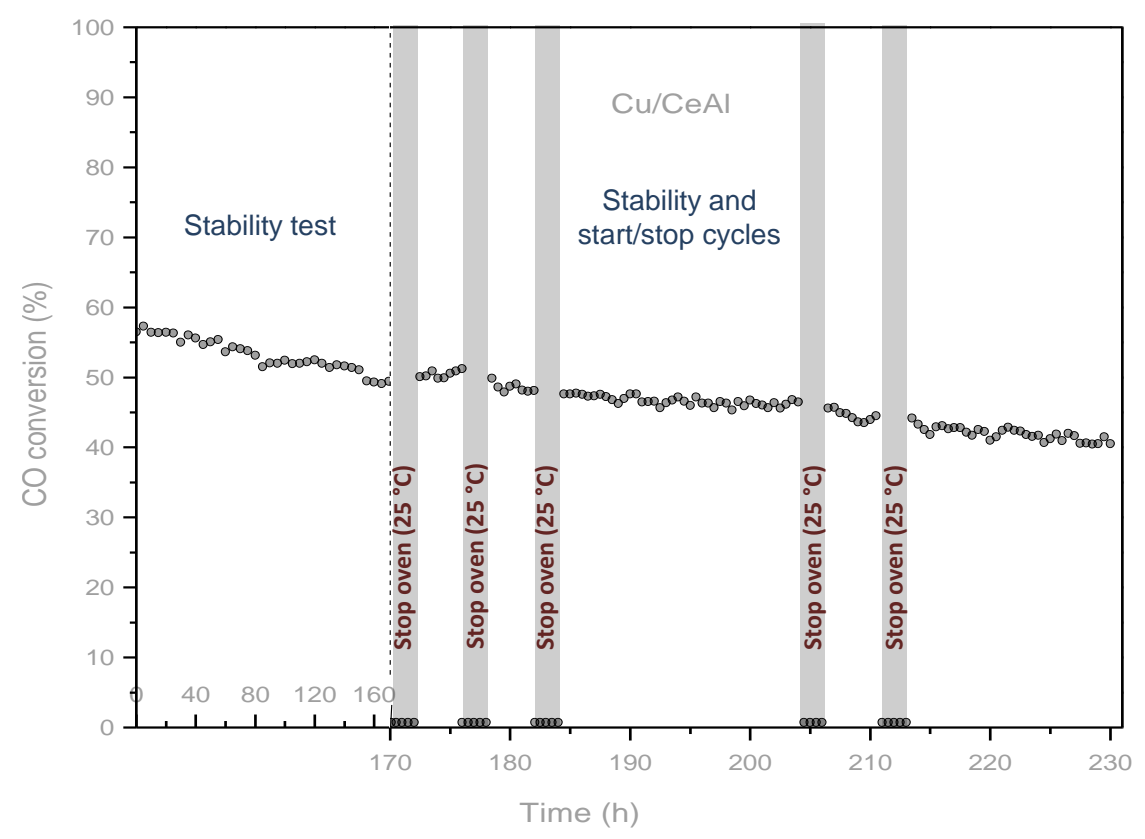

Figure 7. Long-term stability run at $280{ }^{\circ} \mathrm{C}$ with a post-reforming mixture $\left(25 \%\right.$ vol. $\mathrm{H}_{2} \mathrm{O}+8 \%$ vol. $\mathrm{CO}, 37 \% \mathrm{H}_{2}$ and $8 \% \mathrm{CO}_{2}$ ), including some start/stop cycles for the $\mathrm{Cu} / \mathrm{CeAl}$ catalyst.

The smooth deactivation observed is very likely related to $\mathrm{Cu}$ particles sintering. Indeed, we have calculated (using Scherrer equation) the $\mathrm{Cu}$ crystallite size of the $\mathrm{Cu} / \mathrm{CeAl}$ sample before (reduced sample) and after being tested it in the stability test. $\mathrm{Cu}$ metallic cluster presents a particle size of 15 $\mathrm{nm}$ in the reduced sample (diffractogram showed in Figure 1 (b)). After the $230 \mathrm{~h}$ of stability test with several start/stop cycles, the metallic $\mathrm{Cu}$ suffered a slight degree of sintering leading to particle sizes of $31 \mathrm{~nm}$ (diffractogram not shown) Also, very small diffraction peaks related to $\mathrm{CuO}$ appear after this stability test. The later could be due to the start-stop cycles where metallic $\mathrm{Cu}$ may undergo partial oxidation caused by interaction with liquid water during the shutdown stages. Both reasons (a certain degree of sintering and partial oxidation) account for the continuous activity depletion observed during the $230 \mathrm{~h}$ stability test.

In view of the results from Figure 7, it seems obvious that the comparison with bimetallic catalysts in terms of stability is needed. At the same time, such comparison must take place at higher temperatures since the bimetallic catalysts do not show sufficient activity at $280{ }^{\circ} \mathrm{C}$. Figure 8 depicts a comparative long-term stability test of the monometallic, $\mathrm{Cu} / \mathrm{CeAl}$, and bimetallic, $1 \mathrm{Cu} 1 \mathrm{Ni} / \mathrm{CeAl}$ sample including some start-stop cycles during the reaction. As shown in the figure the monometallic suffers for a clear activity decline even before the start-up/shutdowns operations. In fact, at this temperature $\mathrm{Cu}$ sintering is more favoured than in the previous experiments in Figure 7 and therefore there is a significantly stronger deactivation. Very interestingly, the bimetallic material is quite robust and displays a very stable behaviour during $170 \mathrm{~h}$ of reaction. However, upon performing 3 initial start-stop cycles the activity drops from around $60 \%$ of $\mathrm{CO}$ conversion to $c a .48 \%$ and then after a final cycle at $205 \mathrm{~h}$ the catalyst remarkably loss its activity. In any case, the superior stability of the bimetallic sample compared to the monometallic one reflects the benefits of the $\mathrm{Cu}-\mathrm{Ni}$ interaction which seems to go beyond an electronic effect as shown in our XPS data but also such synergy may help to prevent $\mathrm{Cu}$ clusters sintering leading to enhanced stability. 


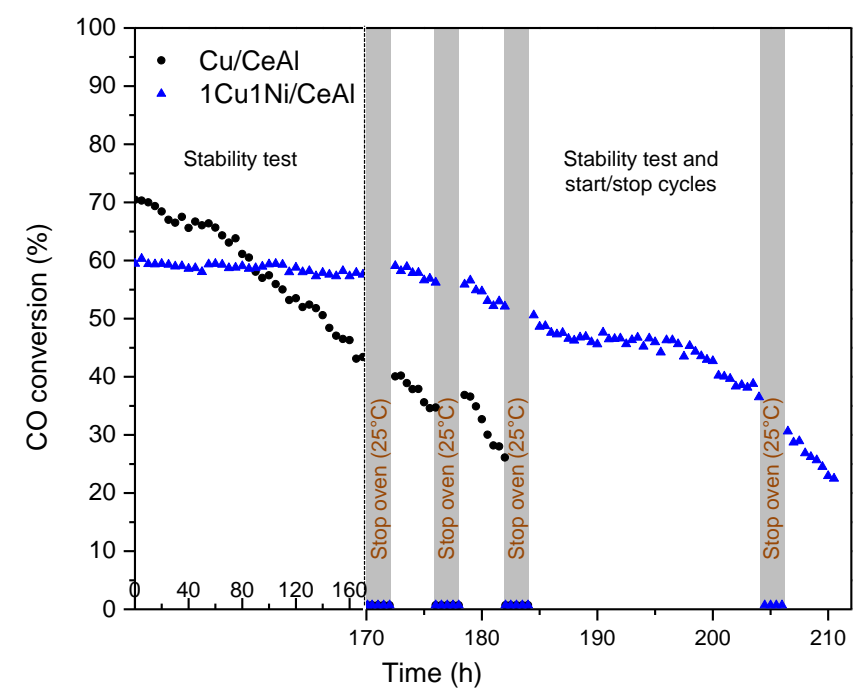

Figure 8. Long-term stability runs at $340{ }^{\circ} \mathrm{C}$ with a post-reforming mixture $\left(25 \%\right.$ vol. $\mathrm{H}_{2} \mathrm{O}+8 \%$ vol. $\mathrm{CO}, 37 \% \mathrm{H}_{2}$ and $8 \% \mathrm{CO}_{2}$ ), including some start/stop cycles for the $\mathrm{Cu} / \mathrm{CeAl}$ and $1 \mathrm{Cu} 1 \mathrm{Ni} / \mathrm{CeAl}$ catalysts.

\section{Conclusions}

Mono and bimetallic $\mathrm{Cu}-\mathrm{Ni}$-based catalysts display rather different performances in the WGS reaction. Despite what a priori could be envisaged in terms of the superior behaviour of the bimetallic systems, our study reveals that bimetallic formulations are not always advantageous. In fact, the monometallic $\mathrm{Cu}$ based catalyst has been found to be more active in both model and post-reforming WGS mixtures at low-medium temperatures than the bi-metallic $\mathrm{Cu}-\mathrm{Ni}$ systems. In addition, the monometallic $\mathrm{Cu}$ catalysts presented high stability and resistance towards transient startup/shutdowns operations - a necessary requisite of a shift catalyst for portable applications.

The monometallic Ni-based catalyst presented good levels of $\mathrm{CO}$ conversion but it also produces methane indicating hydrogen consumption via the undesired methanation reaction. The addition of $\mathrm{Cu}$ to $\mathrm{Ni}$ helps to suppress the methanation reaction since the $\mathrm{Cu}-\mathrm{Ni}$ alloy is completely selective towards the WGS. Among the screened bimetallic compositions it seems that $2 \mathrm{Cu}-1 \mathrm{Ni}$ and $1 \mathrm{Cu}-2 \mathrm{Ni}$ did not result advantageous at all for the shift process. Nevertheless, the bimetallic $1 \mathrm{Cu}-1 \mathrm{Ni}$ presents a good balance activity/selectivity/stability. In particular, this catalyst outperformed the stability of the monometallic $\mathrm{Cu}$ for medium-high temperature shift processes presenting some resistance toward start-stop situations.

Overall, this work showcases a strategy to design mono and bimetallic $\mathrm{Cu}-\mathrm{Ni}$ based for the WGS reaction. Although the intimate contact $\mathrm{Cu}-\mathrm{Ni}$ alters the physicochemical properties of the resulting catalysts, ultimately, the catalyst choice, its performance and suitability for long-term runs is determined by the metallic composition and the reaction conditions.

In fact, the monometallic $\mathrm{Cu}$-based catalyst has been found to be the best material in this study, showing excellent levels of medium-temperature conversion and enough stability for continuous and discontinuous operations. The bimetallic strategy works for $\mathrm{Ni}$ and, actually, the bimetallic catalyst is more interesting than the monometallic $\mathrm{Ni}$ if the $\mathrm{Cu}-\mathrm{Ni}$ alloy is achieved since the alloy suppresses the unwanted parallel methanation reaction which consumes hydrogen. Extreme bimetallic compositions such as $2 \mathrm{Cu}-1 \mathrm{Ni}$ and $1 \mathrm{Cu}-2 \mathrm{Ni}$ did not result advantageous at all for the shift process. 


\section{Acknowledgements}

Financial support for this work was provided by the EPSRC grants EP/J020184/2 and EP/R512904/1 as well as the Royal Society Research Grant RSGR1180353. The Spanish team acknowledges Ministerio de Economía, Industria y Competitividad of Spain (Project MAT2013-45008-P). L. PastorPerez acknowledges Generalitat Valenciana for her postdoctoral grant (APOSTD/2017). Sasol is kindly acknowledged for providing the support.

\section{References}

[1] Y. Hao, B.C. Gates. Activation of dimethyl gold complexes on $\mathrm{MgO}$ for $\mathrm{CO}$ oxidation: Removal of methyl ligands and formation of catalytically active gold clusters. J. Catal. 2009;263;83-91

[2] B. Dou, Y. Song, C. Wang, H. Chen, Y. Xu. Hydrogen production from catalytic steam reforming of biodiesel byproduct glycerol: Issues and challenges Renew. Sustain. Energy Rev. 2014;30;950-960.

[3] D.L. Trimm, Z.I. Önsan, Catal. Onboard fuel conversion for hydrogen-fuel-cell driven vehicles. Rev. Sci. Eng. 2001;43;31-84.

[4] F. Meshkani ,M. Rezaei, M. H. Aboonasr Shiraz, Preparation of high temperature water gas shift catalyst with coprecipitation method in microemulsion system, Chem. Eng. Res. Des. 2016;113;9-16.

[5] L. Pastor-Pérez, R. Buitrago-Sierra, A. Sepúlveda-Escribano, $\mathrm{CeO}_{2}$-promoted Ni/activated carbon catalysts for the water-gas shift (WGS) reaction. Int. J. Hydrog. Energy, 2014;39;17589- 17599

[6] F. Meshkani, M. Rezaei, Preparation of mesoporous nanocrystalline alkali promoted chromium free catalysts $\left(\mathrm{Fe}_{2} \mathrm{O}_{3}-\mathrm{Al}_{2} \mathrm{O}_{3}-\mathrm{NiO}\right)$ for a high temperature water gas shift reaction. RSC Adv., 2015;5; 9955-9964.

[7] M. Zhou, T. Nguyen-Minh Le, L. K. Huynh, B. Liu, Effects of structure and size of Ni nanocatalysts on hydrogen selectivity via water-gas-shift reaction-A first-principles-based kinetic study. Catal. Today 2017;280;210-219.

[8] J.H. Lin, P. Biswas, V.V. Guliants, S. Misture, Hydrogen production by water-gas shift reaction over bimetallic $\mathrm{Cu}-\mathrm{Ni}$ catalysts supported on La-doped mesoporous ceria. Appl. Catal. A: Gen. 2010;387;87-94.

[9] E.T. Saw, U. Oemar, X.R. Tan, Y. Du, a. Borgna, K. Hidajat, S. Kawi, Bimetallic Ni-Cu catalyst supported on $\mathrm{CeO} 2$ for high-temperature water-gas shift reaction: Methane suppression via enhanced CO adsorption. J. Catal. 2014;314;32-46.

[10] T. Liang, Y. Wang, M. Chen, Z. Yang, S. Liu, Z. Zhou, X. Li, Steam reforming of phenolethanol to produce hydrogen over bimetallic $\mathrm{NiCu}$ catalysts supported on sepiolite. Int. J. Hydrog. Energy, 2017;42;28233-28246.

[11] A.A. Lytkina, N.A. Zhilyaeva, M.M. Ermilova, N.V. Orekhova, A.B. Yaroslavtsev, Influence of the support structure and composition of $\mathrm{Ni}-\mathrm{Cu}$-based catalysts on hydrogen production by methanol steam reforming. Int. J. Hydrog. Energy, 2015;40;9677-9684.

[12] D. Li, M. Lu, K. Aragaki, M. Koike, Y. Nakagawa, K. Tomishige, Characterization and catalytic performance of hydrotalcite-derived $\mathrm{Ni}-\mathrm{Cu}$ alloy nanoparticles catalysts for steam reforming of 1methylnaphthalene. Appl. Catal. B: Env. 2016;192;171-181.

[13] Y. Shen, A.C. Lua, Synthesis of Ni and Ni-Cu supported on carbon nanotubes for hydrogen and carbon production by catalytic decomposition of methane. Appl. Catal. B: Env. 2015;164;61-69. 
[14] L.D. Rogatis, T. Montini, B. Lorenzut, P. Fornasiero, $\mathrm{Ni}_{\mathrm{x}} \mathrm{Cu}_{\mathrm{y}} / \mathrm{Al}_{2} \mathrm{O}_{3}$ based catalysts for hydrogen production. Energy Environ. Sci. 2008;1;501-509.

[15] L.C. Chen, S.D. Lin, The ethanol steam reforming over $\mathrm{Cu}-\mathrm{Ni} / \mathrm{SiO}_{2}$ catalysts: Effect of $\mathrm{Cu} / \mathrm{Ni}$ ratio. Appl. Catal. B: Env. 2011;106;639-649.

[16] K.C. Khulbe, R.S. Mann, Nature of Ni-Cu alloys and their role in chemical reactions. Catal. Rev. -Sci. Eng. 1982;24;311-328.

[17] J.H. Sinfelt, J.L. Carter, D.J.C. Yates, Catalytic hydrogenolysis and dehydrogenation over copper-nickel alloys. J. Catal. 1974;24;283-296.

[18] A.R. Naghash, T.H. Etsell, S. Xu, XRD and XPS Study of $\mathrm{Cu}-\mathrm{Ni}$ Interactions on reduced copper-nickel-aluminum oxide solid solution catalysts. Chem. Mater. 2006;18;2480-2488.

[19] T.R. Reina, S. Ivanova, M.A. Centeno, J.A. Odriozola, The role of $\mathrm{Au}, \mathrm{Cu} \& \mathrm{CeO}_{2}$ and their interactions for an enhanced WGS performance. Appl. Catal. B: Env. 2016;187;98-107.

[20] H.E. Swift, F.E. Lutinski, W.L. Kehl, Investigation of the metallic phases in reduced, impregnated nickel and nickel-copper silica-alumina catalysts. J. Phys. Chem. 1965;69;3268-3274.

[21] A. Trovarelli, Catalytic properties of ceria and $\mathrm{CeO}_{2}$-containing materials. Catal. Rev. - Sci. Eng., 1996;38;439-520.

[22] S. Damyanova, C.A. Perez, M. Schmal, J.M.C. Bueno, Characterization of ceria-coated alumina carrier. Appl. Catal., A: Gen. 2002;234;271-282.

[23] R. Molina, G. Poncelet, $\alpha$-Alumina-supported nickel catalysts prepared from nickel acetylacetonate: A TPR study. J. Catal. 1998;173;257-267.

[24] A. Piras, A. Trovarelli, G. Dolcetti, Remarkable stabilization of transition alumina operated by ceria under reducing and redox conditions. Appl. Catal., B: Env. 2000;28;L77-L81.

[25] P. Ratnasamy, D. Srinivas, C.V.V. Satyanarayana, P. Manikandan, R.S. Senthil Kumaran, M. Sachin, V.N. Shetti, Influence of the support on the preferential oxidation of $\mathrm{CO}$ in hydrogen-rich steam reformates over the $\mathrm{CuO}-\mathrm{CeO}_{2}-\mathrm{ZrO}_{2}$ system. J. Catal. 2004;221;455-465.

[26] X. Zheng, X. Zhang, X. Wang, S. Wang, S. Wu, Preparation and characterization of $\mathrm{CuO} / \mathrm{CeO}_{2}$ catalysts and their applications in low-temperature CO oxidation. Appl. Catal. A: Gen. 2005;295;142149.

[27] A.J. Vizcaíno, A. Carrero, J.A. Calles, Hydrogen production by ethanol steam reforming over Cu-Ni supported catalysts. Int. J. Hydrog. Energy 2007;32;1450-1461.

[28] P. Li, J. Liu, N. Nag, P.A. Crozier, In situ preparation of $\mathrm{Ni}-\mathrm{Cu} / \mathrm{TiO}_{2}$ bimetallic catalysts. J. Catal., 2009;262;73-82.

[29] K. Kishi, Y. Motoyoshi, S. Ikeda, Deposition of nickel from $\mathrm{Ni}(\mathrm{CO})_{4}$ on palladium and iron surfaces studied by X-ray photoelectron spectroscopy. Surf. Sci. 1981;105;313-324.

[30] G. Treglia, M.C. Desjonqueres, F. Duncastelle, D. Spanjaad, Correlation effects on Auger spectra in unfilled d band metals. J. Phys. 1981;C14;4347-4355.

[31] C. Price, L. Pastor-Pérez, E. le Saché, A. Sepúlveda-Escribano, T.R. Reina, Highly active Cu$\mathrm{ZnO}$ catalysts for the WGS reaction at medium-high space velocities: Effect of the support composition. Int. J. Hydrog. Energy 2017;42;10747-10751. 
[32] E.T. Saw, U. Oemar, M.L. Ang, K. Hidajat, S. Kawi, Highly Active and Stable Bimetallic Nickel-Copper Core-Ceria Shell Catalyst for High-Temperature Water-Gas Shift Reaction. ChemCatChem. 2015;7;3358 - 3367.

[33] O. Arbeláez, T.R. Reina, S. Ivanova, F. Bustamante, A.L. Villa, M.A. Centeno, J.A. Odriozola, Mono and bimetallic $\mathrm{Cu}-\mathrm{Ni}$ structured catalysts for the water gas shift reaction. Mono and bimetallic Cu-Ni structured catalysts for the water-gas shift reaction. Appl. Catal. A: Gen. 2015;497;1-9.

[34] T. Tabakova, V. Idakiev, J. Papavasiliou, G. Avgouropoulos, T. Ioannides, Effect of additives on the WGS activity of combustion synthesized $\mathrm{CuO} / \mathrm{CeO}_{2}$ catalysts. Catal. Commun. 2007;8;101-106.

[35] M. Gonzalez Castaño, T. R. Reina, S. Ivanova, M. A. Centeno, J. A. Odriozola, Pt vs. Au in water-gas shift reaction. J. Catal. 2014;314;1-9.

[36] T.R. Reina, E. Papadopoulou, S. Palma, S. Ivanova, M.A. Centeno, T. Loannides, J.A. Odriozola, Appl. Catal. B: Env. 2014;150-151;554-563. 


\title{
Bimetallic $\mathrm{Cu}-\mathrm{Ni}$ catalysts for the WGS reaction - cooperative or uncooperative effect?
}

\author{
Laura Pastor-Pérez, ${ }^{\text {a,b }}$ Sai Gu, ${ }^{\mathrm{a}}$ Antonio Sepúlveda-Escribano, ${ }^{\mathrm{b}}$ Tomas R. Reina ${ }^{\mathrm{a}}$ \\ *corresponding author: 1.pastorperez@surrey.ac.uk
}

\begin{abstract}
In this work, bimetallic Cu-Ni catalysts have been studied in the water-gas shift (WGS) reaction, and they have shown different levels of synergy and anti-synergy in terms of catalytic activity and selectivity to the desired products. $\mathrm{Cu}-\mathrm{Ni}$ interactions alter the physicochemical properties of the prepared materials (i.e. surface chemistry, redox behaviour, etc.) and as a result, the catalytic trends are influenced by the catalysts' composition. Our study reveals that $\mathrm{Cu}$ enhances $\mathrm{Ni}$ selectivity to $\mathrm{CO}_{2}$ and $\mathrm{H}_{2}$ by preventing $\mathrm{CO} / \mathrm{CO}_{2}$ methanation, while $\mathrm{Ni}$ does not help to improve $\mathrm{Cu}$ catalytic performance by any means. Indeed, the monometallic $\mathrm{Cu}$ formulation has shown the best results in this study, yielding high levels of reactants conversion and excellent long-term stability. Interestingly, for medium-high temperatures, the bimetallic $1 \mathrm{Cu}-1 \mathrm{Ni}$ outperforms the stability levels reached with the monometallic formulation and becomes an interesting choice even when start-up/shutdowns operations are considered during the catalytic experiments.
\end{abstract}

Keywords: water-gas shift reaction, bimetallic catalysts, $\mathrm{Cu}-\mathrm{Ni}$, synergy, anti-synergy.

\section{Introduction}

In the context of hydrogen fuel processors, the water gas shift reaction has gained a renewed interest given its key role to deliver clean hydrogen streams after the reforming units [1,2]. The exothermic nature of this reaction $(\Delta \mathrm{H}=-41.2 \mathrm{~kJ} / \mathrm{mol})$ makes it thermodynamically favourable at low temperatures but kinetically limited in this temperature window. In order to overcome this drawback, large-scale industrial plants often use a two-step process, comprising one step at $350-400{ }^{\circ} \mathrm{C}$ which is named HTWGS (high-temperature WGS) and employs Fe-Cr-based catalysts, and a second step at lower temperatures, $200-300{ }^{\circ} \mathrm{C}$, which is named LTWGS (low-temperature WGS) and employs $\mathrm{Cu}$ $\mathrm{Zn}$ catalysts [3]. However, such a two steps process is not a viable solution for small applications because of its technical complexity and multiple stages involved. Hence it is very desirable to intensify the process by using only one reaction unit in which the catalyst can operate in a wider temperature range.

The Fe-Cr-based catalyst is the adopted choice for industrial applications in HTWGS reaction [4]. However, the carcinogenic nature and toxicity of chromium, converting this element in the first drawback to solve, have encouraged the catalytic community to find other less harmful alternatives. Ni-based catalysts are being currently investigated as promising systems for the medium-high temperature WGS reaction [5-7]. Excellent levels of $\mathrm{CO}$ conversion can be achieved using $\mathrm{Ni}$ as active phase, but at high temperatures, $\mathrm{CO}$ and $\mathrm{CO}_{2}$ hydrogenation (methanation reactions) appear as undesired processes accounting for an extra hydrogen consumption and, therefore, hampering the implementation of $\mathrm{Ni}$ in realistic applications.

The addition of a second metal such as copper in the catalytic formulation has double-fold beneficial effect: (i) it can suppress the methanation reactions, and (ii) it can improve the overall catalytic activity at lower temperatures. In general, the electronic and geometric perturbations caused by 
bimetallic formulations and alloys in the metals can have an interesting effect on the catalytic activity and selectivity [8]. Specifically, Ni-Cu alloys are receiving great interest in different chemical reactions such a WGS [9], steam reforming of ethanol [10], methanol [11], or 1-methylnaphthalene [12], and methane decomposition [13]. Saw et al [9] reported that $\mathrm{Ni}-\mathrm{Cu}$ alloy can enhance $\mathrm{CO}$ adsorption which prevents $\mathrm{CO}$ dissociation and in turn prevents the formation of carbon species during high-temperature WGS reaction. Furthermore, several studies have shown that $\mathrm{Ni}-\mathrm{Cu}$ alloy is able to improve the catalyst's stability and selectivity in ethanol steam reforming $[14,15]$. On the contrary, some controversial results for $\mathrm{Ni}-\mathrm{Cu}$ alloy catalysts have also been reported. For example, the addition of copper to nickel significantly reduced the catalytic activity in styrene hydrogenation and ethane hydrogenolysis to methane [16,17]. The decrease in catalytic activity was explained by changes in the electronic properties of nickel upon the addition of copper, making Ni electron deficient this preventing reactants' activation [18].

This collection of diverse and conflicting results sparks further research on copper-nickel materials. In this work, we have analysed the effect of the bimetallic formulation on the catalytic activity and selectivity (suppression of methanation reaction) during the WGS of a series of $\mathrm{Ni}-\mathrm{Cu}$-based catalysts. The influence of adding $\mathrm{Cu}$ to a $\mathrm{Ni} / \mathrm{CeO}_{2}-\mathrm{Al}_{2} \mathrm{O}_{3}$ catalyst and $\mathrm{Ni}$ to a $\mathrm{Cu} / \mathrm{CeO}_{2}-\mathrm{Al}_{2} \mathrm{O}_{3}$ catalyst, as well as the impact of the $\mathrm{Ni} / \mathrm{Cu}$ ratio are also subject of this study, in which we have also evidenced the relationship between the catalytic activity exhibited by the multi-component materials and their electronic and structural features. Furthermore, we aim to examine whether there are advantages for bimetallic formulations when broad temperature range application is desired.

\section{Experimental}

\subsection{Catalyst preparation}

A $\mathrm{CeO}_{2}-\mathrm{Al}_{2} \mathrm{O}_{3}$ support was prepared via wet impregnation in excess of solvent. The necessary amount of cerium nitrate (Sigma-Aldrich) aiming to obtain $20 \mathrm{wt} . \%$ of $\mathrm{CeO}_{2}$ was impregnated on $\gamma$-alumina powder (Sasol). The impregnation was carried out in $50 \mathrm{~mL}$ of ethanol, evaporated at reduced pressure in a rotary evaporator at $50{ }^{\circ} \mathrm{C}$ till obtaining a dry solid. The support was then filtered, dried and calcined at $500{ }^{\circ} \mathrm{C}$ for $4 \mathrm{~h} . \mathrm{CeO}_{2}-\mathrm{Al}_{2} \mathrm{O}_{3}$ was selected due to their suitability as support for the WGS reaction [19].

Similarly, the catalysts were synthesised by wet impregnation in excess of solvent. The necessary amount of $\mathrm{Ni}$ and $\mathrm{Cu}$ nitrates (Sigma Aldrich) were dissolved in ethanol to obtain a total amount of 15 wt.\% of the active phase. $\mathrm{CeO}_{2}-\mathrm{Al}_{2} \mathrm{O}_{3}$ support was added to the different solutions, with stirring. After $12 \mathrm{~h}$, the excess of solvent was slowly removed under vacuum at $50{ }^{\circ} \mathrm{C}$ and the solids were then dried in the oven overnight at $80^{\circ} \mathrm{C}$. Finally, the dried solids were calcined for $4 \mathrm{~h}$ at $500{ }^{\circ} \mathrm{C}$. In this way, we obtained a series of mono- and bimetallic catalysts with different $\mathrm{Cu}-\mathrm{Ni}$ molar ratios that were labelled as follow: $\mathrm{Ni} / \mathrm{CeAl}, 1 \mathrm{Cu} 2 \mathrm{Ni} / \mathrm{CeAl}, 1 \mathrm{Cu} 1 \mathrm{Ni} / \mathrm{CeAl}, 2 \mathrm{Cu} 1 \mathrm{Ni} / \mathrm{CeAl}$ and $\mathrm{Cu} / \mathrm{CeAl}$.

\subsection{Characterisation}

The textural characterization of the catalysts was carried out by $\mathrm{N}_{2}$ adsorption at $-196{ }^{\circ} \mathrm{C}$ with an AUTOSORB-6 equipment (QUANTACHROME INSTRUMENTS). Samples were previously outgassed at $250{ }^{\circ} \mathrm{C}$ for $4 \mathrm{~h}$.

X-Ray Diffraction (XRD) analysis was undertaken using an X'Pert Pro PANalytical. The diffraction patterns were recorded with $\mathrm{Cu} K \alpha(40 \mathrm{~mA}, 45 \mathrm{kV})$ over a 2 theta range of 5 to $80^{\circ}$, a position sensitive detector using a step size of $0.05^{\circ}$ and a step time of $240 \mathrm{~s}$. The powder XRD patterns were further processed using the accompanying software for the equipment, X'PertHighscore Plus ${ }^{\odot}$. 
The TPR experiments were carried out in a U-shaped quartz cell using a $5 \% \mathrm{H}_{2} / \mathrm{He}$ gas flowing at 50 $\mathrm{mL} \cdot \mathrm{min}^{-1}$, with a heating rate of $10{ }^{\circ} \mathrm{C} \cdot \mathrm{min}^{-1} .50 \mathrm{mg}$ of catalysts were loaded in the quartz reactor that was heated from room temperature to $1000{ }^{\circ} \mathrm{C}$. Hydrogen consumption was followed by on-line mass spectrometry (Pfeiffer, OmniStar GSD 301). CuO standard (99.999\%) was employed for the TPR calibration.

X-ray photoelectron spectroscopy (XPS, K-ALPHA, Thermo Scientific) was used to analyze the samples' surface. All spectra were collected using Al-K radiation $(1486.6 \mathrm{eV})$, monochromatized by a twin crystal monochromator, yielding a focused X-ray spot (elliptical in shape with a major axis length of $400 \mu \mathrm{m}$ ) at $3 \mathrm{~mA} \times 12 \mathrm{kV}$. The alpha hemispherical analyser was operated in the constant energy mode with survey scan pass energies of $200 \mathrm{eV}$ to measure the whole energy band and $50 \mathrm{eV}$ in a narrow scan to selectively measure the particular elements. XPS depth profiles were obtained by sputtering the specimen with a $1 \mathrm{keV} \mathrm{Ar}{ }^{+}$ion beam. XPS data were analysed with Avantage software. A smart background function was used to approximate the experimental backgrounds and surface elemental composition was calculated from background-substracted peak areas. Charge compensation was achieved with the system flood gun that provides low energy electrons and low energy argon ions from a single source. The samples were reduced ex-situ at the reaction temperature $\left(425{ }^{\circ} \mathrm{C}\right)$ and conserved in octane until the analysis.

A simultaneous TG-DTA coupled to a Mass Spectrometer (TG-DTA-MS), was used for the TGA/TPO analysis. The TG-DTA is a TGA/SDTA851and/LF/1600 from METTLER TOLEDO. The Mass Spectrometer is a PFEIFFER VACUUM THERMOSTAR GSD301T quadrupole able to measure a range of mass/charge ratios between 1 and 300 which provides the option of quantitative analysis. The mass spectrometer was calibrated using calcium oxalate standard. Approximately $10 \mathrm{mg}$ of each sample was heated in $100 \mathrm{~mL} / \mathrm{min} \mathrm{O}_{2} / \mathrm{He}$ flows up to $1000{ }^{\circ} \mathrm{C}$ at $10{ }^{\circ} \mathrm{C} / \mathrm{min}$. The desorbed species were identified with the mass spectrometer described above.

\subsection{Catalytic activity}

The catalytic behaviour of the prepared samples covering low and high-temperature water-gas shift reaction was evaluated in a fixed bed flow reactor under atmospheric pressure in the range of temperatures from $200{ }^{\circ} \mathrm{C}$ to $400{ }^{\circ} \mathrm{C}$. Prior to reaction, the catalysts $(0.5 \mathrm{~g})$ were reduced under flowing $\mathrm{H}_{2}\left(50 \mathrm{~mL} \cdot \mathrm{min}^{-1}\right)$ for $1 \mathrm{~h}$ at $400{ }^{\circ} \mathrm{C}$. For the catalytic screening, a model mixture comprised of $25 \%$ vol. $\mathrm{H}_{2} \mathrm{O}+5 \%$ vol. $\mathrm{CO}$ was utilised. A post reforming surrogate stream was also utilised consisting of $25 \%$ vol. $\mathrm{H}_{2} \mathrm{O}+8 \%$ vol. $\mathrm{CO}, 37 \% \mathrm{H}_{2}$ and $8 \% \mathrm{CO}_{2}$. For all the WGS runs the gas hourly space velocity (GHSV) was $12000 \mathrm{~h}^{-1}$.

\section{Results and discussion}

3.1 Catalysis characterization

Table 1. Textural properties of supports and catalysts.

\begin{tabular}{lccc}
\hline Samples & BET $\left(\mathbf{m}^{2} / \mathbf{g}\right)$ & Total Pore Volume $\left(\mathbf{c m}^{\mathbf{3}} / \mathbf{g}\right)$ & Pore Size $(\mathbf{n m})$ \\
\hline $\mathrm{Al}_{2} \mathrm{O}_{3}$ & 216 & 0.513 & 6.15 \\
$\mathrm{CeO}_{2}-\mathrm{Al}_{2} \mathrm{O}_{3}$ & 159 & 0.361 & 6.14 \\
$\mathrm{Ni} / \mathrm{CeAl}$ & 141 & 0.308 & 6.14 \\
$1 \mathrm{Cu} 2 \mathrm{Ni} / \mathrm{CeAl}$ & 139 & 0.300 & 6.12 \\
$1 \mathrm{Cu} 1 \mathrm{Ni} / \mathrm{CeAl}$ & 138 & 0.306 & 6.12 \\
$2 \mathrm{Cu} 1 \mathrm{Ni} / \mathrm{CeAl}$ & 134 & 0.302 & 6.03 \\
\hline
\end{tabular}


Table 1 provides the textural properties of the bare $\mathrm{Al}_{2} \mathrm{O}_{3}, \mathrm{CeO}_{2}-\mathrm{Al}_{2} \mathrm{O}_{3}$ supports and all the synthesised catalysts. Both supports and their corresponding $\mathrm{Ni}, \mathrm{Ni}-\mathrm{Cu}$ and $\mathrm{Cu}$ catalysts exhibit type IV isotherms (not shown), typically ascribed to mesoporous materials according to IUPAC classifications. The surface areas of the prepared materials ranged from $115-216 \mathrm{~m}^{2} \mathrm{~g}^{-1}$ while the primary pore diameters estimated from the maximum in the BJH pore size distribution are around 6 $\mathrm{nm}$. The textural properties are governed by the primary $\gamma$-alumina support. The expected decrease in surface area and pore volume after metal and oxide introduction is related to partial blockage of pores of the $\mathrm{Al}_{2} \mathrm{O}_{3}$ support and dilution effect due to the high metal loading. Overall changes on the textural properties within the studied series are not remarkable and in principle, we do not expect an impact of the textural features on the catalytic performance.

Figure $1 \mathrm{~A}$ shows the $\mathrm{X}$-Ray diffraction patterns of the calcined catalysts and the bare $\mathrm{CeO}_{2}-\mathrm{Al}_{2} \mathrm{O}_{3}$ support. All the samples present the typical diffraction peaks of the ceria fluorite cubic structure (JCPDS\# 00-004-0593) and those of the primary $\gamma-\mathrm{Al}_{2} \mathrm{O}_{3}$ support (JCPDS\# 00-048-0367). As for the $\mathrm{Cu}$-containing samples, some peaks related to monoclinic CuO (JCPDS\# 80-1917) were detected in the monometallic $\mathrm{Cu} / \mathrm{CeAl}$ sample and also in the bimetallic $2 \mathrm{Cu} 1 \mathrm{Ni} / \mathrm{CeAl}$ (small peaks). As for the $\mathrm{Ni}$-containing samples, no reflections related to $\mathrm{NiO}$ species were detected. This lack of $\mathrm{NiO}$ peaks indicates the good dispersion and small particle size of $\mathrm{Ni}$ species in the prepared materials.

Figure 1B presents the diffraction patterns of the samples after a $1 \mathrm{~h}$ of reduction treatment emulating the pre-activation step before every WGS run. Some interesting remarks are extracted from these data. First, the pre-activation in hydrogen does not produce any sintering neither on $\mathrm{CeO}_{2}$ nor on $\mathrm{Ni}$ species, a fact that will help to achieve good performance in the shift reaction. Also, the reduction of $\mathrm{CuO}$ to $\mathrm{Cu}^{0}$ is evidenced for the $\mathrm{Cu} / \mathrm{CeAl}$ and the $2 \mathrm{Cu} 1 \mathrm{Ni} / \mathrm{CeAl}$ samples, with peaks at $2 \theta=43.3^{\circ}$ and $50.4^{\circ}$ attributed to metallic copper (JCPDS\# 4-0836). Zooming into the 2theta region between $40^{\circ}-54^{\circ}$ (Fig 1C), a small shift of the metallic $\mathrm{Cu}$ phase can be observed in the $2 \mathrm{Cu} 1 \mathrm{Ni} / \mathrm{CeAl}$ sample, showing a diffraction peak shifted at intermediate positions between those for pure $\mathrm{Cu}$ and $\mathrm{Ni}$ thus indicating the formation of $\mathrm{Cu}-\mathrm{Ni}$ alloy [7]. Since in the rest of the samples no peaks for $\mathrm{Ni}$ and $\mathrm{Cu}$ were detected, the presence of the alloy should not be discarded. It is noteworthy that at high nickel concentrations a homogeneous solid solution of copper and nickel can be formed, whereas as the $\mathrm{Ni} / \mathrm{Cu}$ ratio approaches 1 , copper has a tendency to be segregated in order to minimize the interface surface energy $[20,18]$. 

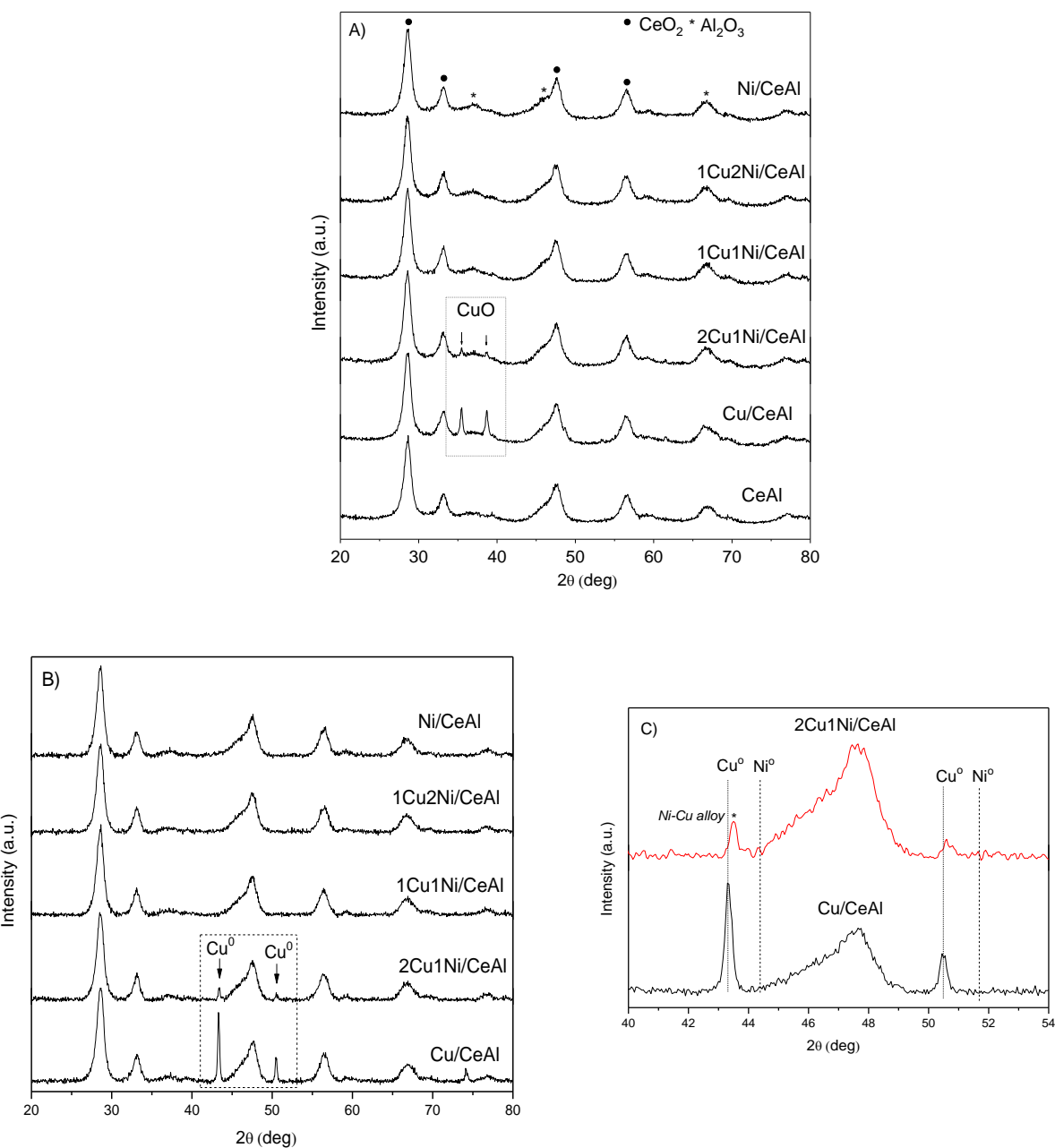

Figure 1. XRD of A) calcined samples, B) reduced samples and, C) $40^{\circ}-54^{\circ}$ region of the XRD patterns of reduced samples.

The redox properties and the metal-support interactions were studied by means of $\mathrm{H}_{2}$-TPR as depicted in Figure 2. The TPR profiles and the total reducibility percentages $(\mathrm{R}(\%))$ reveal substantially different redox properties among the studied materials. More precisely, the TPR profile (Figure 2 (a)) of the $\mathrm{Ni} / \mathrm{CeAl}$ sample is governed by two broad reduction zones, a low temperature one ca 200-400 ${ }^{\circ} \mathrm{C}$ and a high-temperature reduction event between 450 and $850{ }^{\circ} \mathrm{C}$, with a shoulder at $900{ }^{\circ} \mathrm{C}$. The first reduction zone is related to the reduction $\mathrm{Ni}^{2+}$ to metallic $\mathrm{Ni}$ for the small $\mathrm{Ni}$ particles, accompanied by the reduction of surface ceria. It is seen that $\mathrm{CeO}_{2}$ loading shifts the nickel reduction to lower temperature values, indicating some changes in the catalyst's properties promoted by $\mathrm{CeO}_{2}$ as reported elsewhere [21,22]. The second reduction zone is ascribed to $\mathrm{NiO}$ particles with a strong support influence and also to the ceria bulk reduction [23]. The shoulder at high temperature has been previously attributed to the reduction of $\mathrm{CeAlO}_{3}[24,22]$, although this phase has not been identified by XRD. 


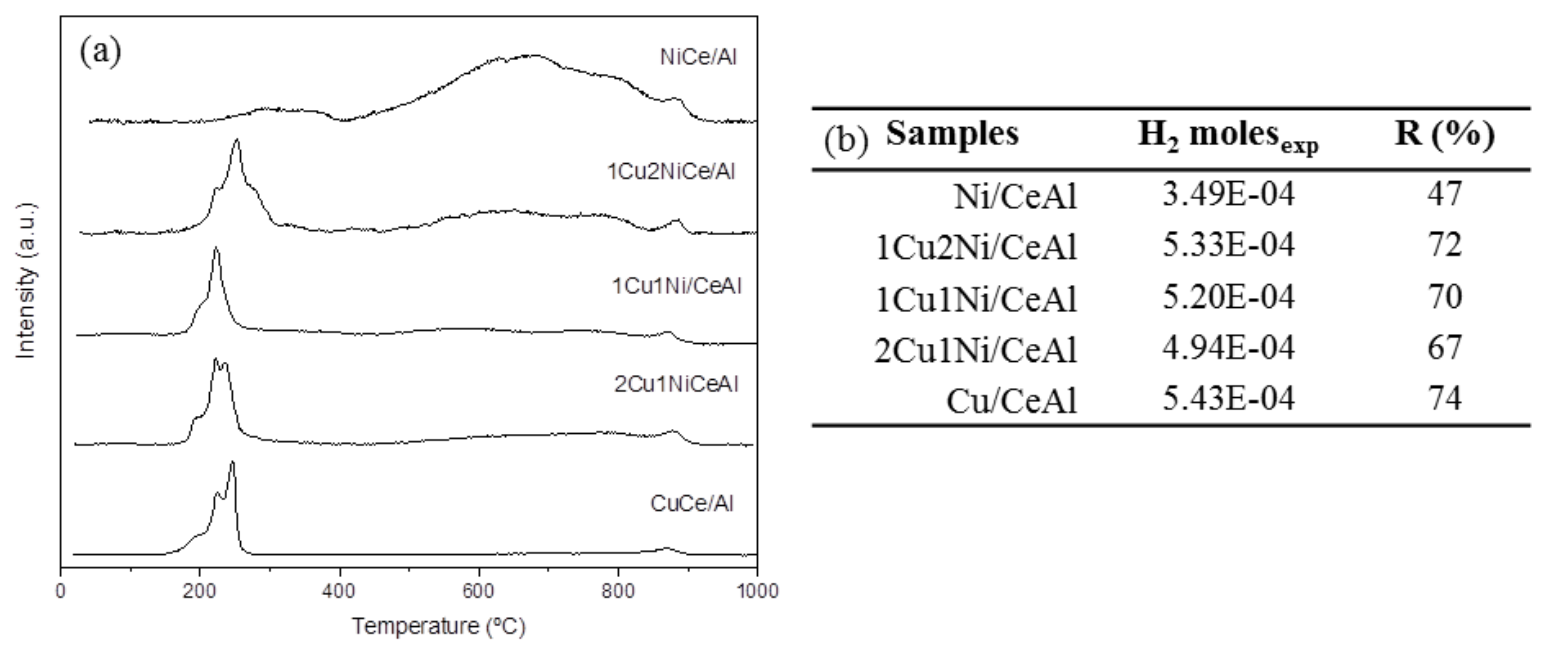

Figure 2. (a) $\mathrm{H}_{2}$-TPR profiles and (b) $\mathrm{H}_{2}$ experimental moles consumed and overall reducibility of the studied samples.

The reduction profile of the other monometallic catalyst, $\mathrm{Cu} / \mathrm{CeAl}$, was characterised by one reduction zone containing several peaks between 160 and $280{ }^{\circ} \mathrm{C}$. It is widely accepted that the shoulder at lower temperatures represents the reduction of $\mathrm{CuO}$ nanoparticles highly dispersed on the $\mathrm{CeAl}$ support, while the two peaks at higher temperatures represent the reduction of bulk $\mathrm{CuO}$ particles and surface $\mathrm{CeO}_{2}$ interacting to different extent $[25,26]$. Furthermore, for the bimetallic catalysts, the addition of $\mathrm{Cu}$ to the Ni-containing samples shifts the reduction events towards lower temperatures. The TPR profiles of the bimetallic samples show that the presence of $\mathrm{Cu}$ as a second metal lowered the reduction temperature of $\mathrm{Ni}$ as was previously shown. Very likely, $\mathrm{Cu}$ disrupts the strong Ni$\mathrm{Al}_{2} \mathrm{O}_{3}$ interaction and changes the situation in such a way that for the bimetallic systems $\mathrm{NiO}_{\mathrm{x}}-\mathrm{CuO}_{\mathrm{x}}$ particles are in intimate contact and present weaker metal-support interaction. The latter explains the easier reduction of $\mathrm{NiO}_{x}$ particles in the presence of $\mathrm{CuO}_{x}$ [27,28]. Irrespectively of the mechanism, the improvement of reducibility of $\mathrm{NiO}$ when $\mathrm{CuO}$ is added mirrors a synergistic interaction between the metal oxide phases that not only alters their redox properties but also explains the decrease of their crystallite size observed by XRD. Indeed, a more homogeneous peak (presence of only one peak at higher temperatures) was observed for the $1 \mathrm{Cu} 1 \mathrm{Ni}$ composition, suggesting a much stronger interaction between $\mathrm{CuO}$ and $\mathrm{NiO}$ [7]. This observation is also corroborated when the total reducibility, $\mathrm{R}(\%)$ is calculated. As shown in Figure 2 (b), the addition of $\mathrm{Cu}$ to $\mathrm{Ni} / \mathrm{CeAl}$ sample increases notoriously the reducibility of the sample, being substantially boosted for the $1 \mathrm{Cu} 2 \mathrm{Ni} / \mathrm{CeAl}$ and $1 \mathrm{Cu} 1 \mathrm{Ni} / \mathrm{CeAl}$ samples. However, for copper-rich bimetallic compositions $(\mathrm{Cu}>\mathrm{Ni})$, the reducibility slightly decreases, due to the copper segregation happening for this sample as discussed and corroborated in the XPS section. In any case, there is a clear impact of the $\mathrm{Ni}-\mathrm{Cu}$ contact on the redox properties of the samples.

The XPS studies revealed the chemical state of nickel and copper upon reduction, as well as changes in the electronic properties of nickel in the presence of copper and aluminium species. 


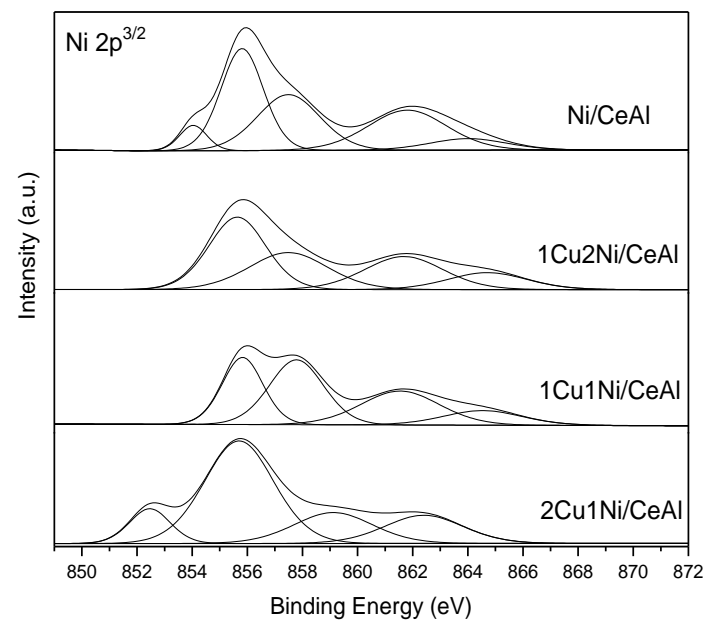

Figure 3. XPS core level of the Ni $2 \mathrm{p}_{3 / 2}$ region for catalysts reduced at $450{ }^{\circ} \mathrm{C}$.

The Ni $2 p_{3 / 2}$ spectra for all samples reduced at $450{ }^{\circ} \mathrm{C}$ (Figure 3 ) are characterised by a main peak corresponding to the final state $2 p^{5} 3 d^{9} \mathrm{~L}$ (L means a ligand hole) and a satellite at higher binding energy (B.E.) corresponding to $2 p^{5} 3 d^{8}$ L. Furthermore, Figure 3 shows the curve fitting of the experimental spectra and the B.E. values obtained from these curves are compiled in Table 2.

Table 2. Binding energies of the Ni $2 p_{3 / 2}$ and $\mathrm{Cu} 2 p_{3 / 2}$ levels in the catalysts reduced at $450{ }^{\circ} \mathrm{C}$.

\begin{tabular}{|c|c|c|}
\hline Samples & Ni $2 p_{3 / 2}$ & $\mathrm{Cu} \mathrm{2p_{3/2 }}$ \\
\hline $\mathrm{Ni} / \mathrm{CeAl}$ & $854.0-855.8-857.5$ & - \\
\hline $1 \mathrm{Cu} 2 \mathrm{Ni} / \mathrm{CeAl}$ & $855.6-857.5$ & $931.2-933.1-935.2$ \\
\hline $1 \mathrm{Cu} 1 \mathrm{Ni} / \mathrm{Ce} \mathrm{Al}$ & $855.8-857.8$ & 931.9 - $933.9-936.2$ \\
\hline $2 \mathrm{Cu} 1 \mathrm{Ni} / \mathrm{CeAl}$ & $852.5-855.7$ & 931.9 - 933.4- 935.3 \\
\hline $\mathrm{Cu} / \mathrm{CeAl}$ & -- & $932.1-933.8-935.4$ \\
\hline
\end{tabular}

For the $\mathrm{Ni} / \mathrm{CeAl}$ sample, a small peak appears at $854.0 \mathrm{eV}$ which is attributed to metallic Ni. This high B.E. value and the small amount of reduced $\mathrm{Ni}$ obtained are due to the presence $\mathrm{Ni}$ atoms surrounded by $\mathrm{Al}^{3+}$ or $\mathrm{Ce}^{4+}$ (through $\mathrm{O}^{2-}$ linkage) as the second neighbours, causing strong $\mathrm{Ni}-\mathrm{Al}$ or $\mathrm{Ni}-\mathrm{Ce}$ interactions. The following two peaks, at around 855.8 and $857.5 \mathrm{eV}$ are assigned to $\mathrm{Ni}^{2+}$ species.

Regarding the bimetallic $\mathrm{Cu}-\mathrm{Ni}$ samples, it can be seen that the Ni spectra shape changed and the B.E. are shifted to higher values as the amount of copper increases (see Table 2), this suggesting that nickel is at different oxidation states in these samples. As previously reported elsewhere, an increase in the B.E. of the main Ni peak was observed in Ni-Pd alloys $[29,30]$, which has been related to the reduction in $\mathrm{Ni} d$ hole density, namely, a charge transfer to adjacent electronegative $\mathrm{Pd}$ atoms from $\mathrm{Ni}$. In the case of this study, the increase in the binding energies for $\mathrm{Ni}$ also can be related to changes in the $\mathrm{Ni} d$-band arising from the charge transfer from $\mathrm{Ni}$ to the adjacent $\mathrm{Cu}$ atoms. However, at higher copper amounts $(\mathrm{Cu}>\mathrm{Ni})$, the B.E. value tends to restore to those values corresponding to metallic Ni $(852.5 \mathrm{eV})$ due to copper segregation. This behaviour was also confirmed by the XRD results obtained for the $2 \mathrm{Cu} 1 \mathrm{Ni} / \mathrm{CeAl}$ catalyst. 
The $\mathrm{Cu}$ monometallic catalyst exhibits the main peaks at around 932.1 and $933.8 \mathrm{eV}$, and a satellite peak at higher binding energies (Figure 4). According to the literature data, metallic $\mathrm{Cu}$ and $\mathrm{Cu}_{2} \mathrm{O}$ are characterized by the $\mathrm{Cu} 2 p_{3 / 2}$ binding energy in the range of $932.4-932.8 \mathrm{eV}$, while the binding energy for $\mathrm{CuO}$ is between 933.6 and $934.6 \mathrm{eV}$ [5]. In contrast, a continuous decline in the binding energy with the increase of the amount of $\mathrm{Ni}$ relative to metallic $\mathrm{Cu}$ and $\mathrm{Cu}_{2} \mathrm{O}$ is observed for the reduced bimetallic $\mathrm{Ni}-\mathrm{Cu}$ catalysts. This fact is in agreement with a charge transfer from $\mathrm{Ni}$ to the adjacent $\mathrm{Cu}$, matching well with the Ni XPS profiles discussed above.

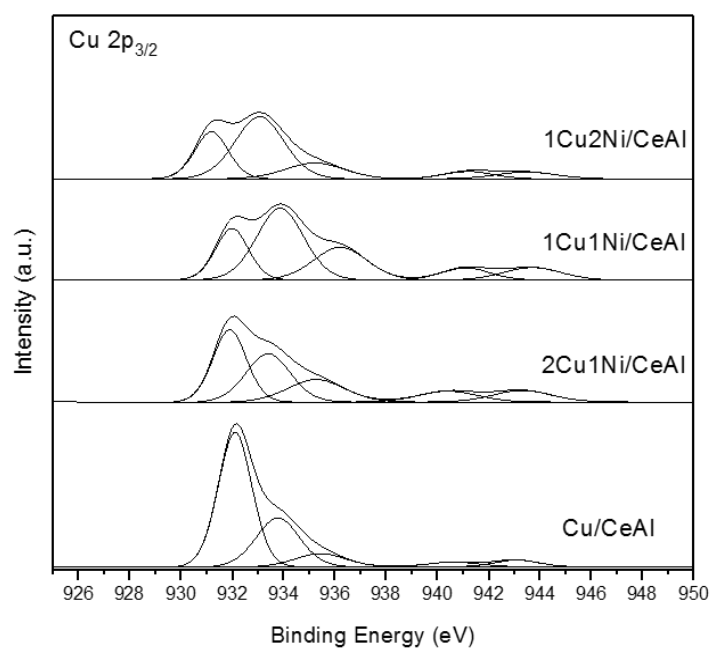

Figure 4. XPS $\mathrm{Cu} 2 \mathrm{p}_{3 / 2}$ spectra for all $\mathrm{Cu}$-containing samples reduced at $450{ }^{\circ} \mathrm{C}$.

\subsection{Catalytic behaviour}

In a first screening, the catalytic behaviour of the monometallic and bimetallic samples was determined at 200-400 ${ }^{\circ} \mathrm{C}$ in a model mixture comprised of $25 \%$ vol. $\mathrm{H}_{2} \mathrm{O}+5 \%$ vol. $\mathrm{CO}$ at a relatively high space velocity $\left(12000 \mathrm{~h}^{-1}\right)$. Figure 5 shows the $\mathrm{CO}$ conversion in the WGS reaction as a function of temperature for all samples. As shown in the Figure, the monometallic $\mathrm{Cu}$-based catalyst is the best system within the studied series, exhibiting high levels of $\mathrm{CO}$ conversion even in the hightemperature range. This result corroborates the suitability of $\mathrm{Cu}$ as an active phase for WGS and the advanced behaviour of $\mathrm{Cu}-\mathrm{CeO}_{2}-\mathrm{Al}_{2} \mathrm{O}_{3}$ mixtures to overcome the space velocity restrictions of the WGS reaction, as recently demonstrated [31]. 


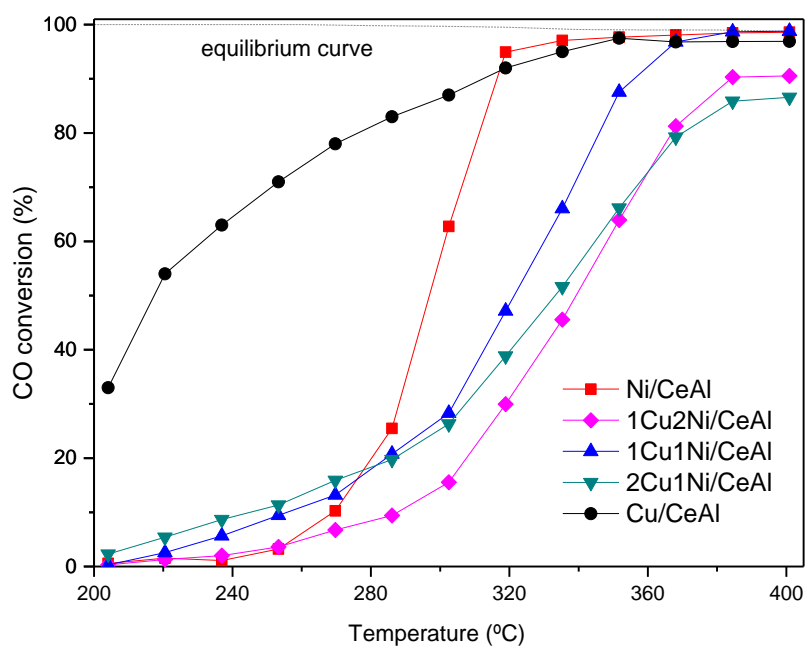

Figure 5. CO conversion as a function of temperature for all samples.

Interestingly, different sort of scenarios are found for the bimetallic and the monometallic $\mathrm{Ni}$ catalysts. Indeed, they all have a much more delayed light-off and only the monotallic $\mathrm{Ni}$ and the $1 \mathrm{Cu} 1 \mathrm{Ni}$ systems reached equilibrium conversions. It has to be mentioned that the monometallic $\mathrm{Ni}$ catalyst favoured the formation of $\mathrm{CH}_{4}$ consuming hydrogen (starting the hydrogenation at $280{ }^{\circ} \mathrm{C}$ with $1 \%$ of methane and reaching a $5 \%$ at $320{ }^{\circ} \mathrm{C}$ ). This trend was previously observed [4] and actually reflects the disadvantage of $\mathrm{Ni}$ versus $\mathrm{Cu}$ to favour parallel reactions. A strategy to suppress methanation for Ni-based catalysts is to incorporate small amounts of $\mathrm{Cu}$ and to form the $\mathrm{Cu}-\mathrm{Ni}$ alloy that suppresses the hydrogenation activity during the reaction [9]. For the rest of the samples (bimetallic $\mathrm{Cu}-\mathrm{Ni}$ and monometallic $\mathrm{Cu}$ ) no methane formation was detected. In particular, our $1 \mathrm{Cu} 1 \mathrm{Ni} / \mathrm{CeAl}$ catalyst presented the highest levels of $\mathrm{CO}$ conversion and did not produce methane in the whole studied temperature range. In fact, this catalyst was the only one in which the $\mathrm{Cu}-\mathrm{Ni}$ alloy was detected by XRD and also was the system with the stronger modification of Ni electronic features according to the XPS analysis. Therefore, the physicochemical characterisation matches with the observed catalytic behaviour and points out the suitability of the $\mathrm{Cu}-\mathrm{Ni}$ alloy to improve the performance of monometallic Ni-based catalysts for the shift reaction. On the contrary, the extreme compositions $2 \mathrm{Cu}-1 \mathrm{Ni}$ and $1 \mathrm{Cu}-2 \mathrm{Ni}$ did not contribute to improving the overall activity of the multicomponent catalysts. This observation reflects the need to carefully optimise the chemical composition of bimetallic catalysts to actually obtain some benefits from the mixed active phases, otherwise, the bi-metallic strategy could result detrimental as reflected in this study.

Table 3. Comparison with state of art materials published in the literature.

\begin{tabular}{|c|c|c|c|c|c|}
\hline Catalyst & Temp. range & Gas mixture & CO conversion & GHSV $\left(h^{-1}\right)$ & Reference \\
\hline $\begin{array}{l}10 \%- \\
(5 \mathrm{Cu} 5 \mathrm{Ni}) @ \mathrm{CeO}_{2} \\
\text { (shell catalyst) }\end{array}$ & $300-500$ & $\begin{array}{l}5 \text { mol\% } \mathrm{CO}, 25 \\
\text { mol\% } \mathrm{H}_{2} \mathrm{O} \\
\text { balanced in } \mathrm{He}\end{array}$ & $\begin{array}{l}\text { Highest } \mathrm{CO} \\
\text { conversion }(92 \%) \text { achieved } \\
\text { at } 500{ }^{\circ} \mathrm{C}\end{array}$ & $*$ n.a. & [32] \\
\hline $\begin{array}{l}10 \% \\
(5 \mathrm{Ni} 5 \mathrm{Cu}) / \mathrm{CeO}_{2}\end{array}$ & $300-500$ & $\begin{array}{l}5 \text { mol\% } \mathrm{CO}, 25 \\
\text { mol\% } \mathrm{H}_{2} \mathrm{O} \\
\text { balanced in } \mathrm{He}\end{array}$ & $\begin{array}{l}\text { Highest } \mathrm{CO} \\
\text { conversion }(81 \%) \text { achieved } \\
\text { at } 500{ }^{\circ} \mathrm{C}\end{array}$ & $*$ n.a. & [32] \\
\hline $\begin{array}{l}\text { 20(wt.\%)Cu2- } \\
\text { Ni1/AC }\end{array}$ & $180-350$ & $\begin{array}{l}4.5 \text { vol\% } \mathrm{CO}, 31.1 \\
\mathrm{kPa} \text { steam in } \\
\text { balanced in } \mathrm{N}_{2}\end{array}$ & $\begin{array}{l}\text { Highest } \mathrm{CO} \\
\text { conversion }(70 \%) \text { achieved } \\
\text { at } 350{ }^{\circ} \mathrm{C}\end{array}$ & 4000 & [33] \\
\hline
\end{tabular}




\begin{tabular}{|c|c|c|c|c|c|}
\hline $\begin{array}{l}20(w t . \%) C u 2- \\
\text { Ni1/AC }\end{array}$ & $180-350$ & $\begin{array}{l}4.5 \text { vol\% } \mathrm{CO}, 31.1 \\
\mathrm{kPa} \text { steam in } \\
\text { balanced in } \mathrm{N}_{2}\end{array}$ & $\begin{array}{l}\text { Highest } \mathrm{CO} \\
\text { conversion }(54 \%) \text { achieved } \\
\text { at } 3500^{\circ} \mathrm{C}\end{array}$ & 4000 & [33] \\
\hline $\begin{array}{l}\mathrm{Cu}-\mathrm{ZnO} / \mathrm{Al}_{2} \mathrm{O}_{3} \\
\text { commercial } \\
\text { catalysts }\end{array}$ & $150-300$ & $\begin{array}{l}4.42 \text { vol\% CO, } 31.1 \\
\mathrm{kPa} \text { steam in } \\
\text { balanced in } \mathrm{He}\end{array}$ & $\begin{array}{l}\text { Highest conversion }(92 \%) \\
\text { achieved at } 2500^{\circ} \mathrm{C}\end{array}$ & 4000 & [34] \\
\hline $\mathrm{Pt}(2 \mathrm{wt} . \%) / \mathrm{Al}_{2} \mathrm{O}_{3}$ & $180-340$ & $\begin{array}{l}4.5 \text { vol\% } \mathrm{CO}, 31.1 \\
\mathrm{kPa} \text { steam in } \\
\text { balanced in } \mathrm{N}_{2}\end{array}$ & $\begin{array}{l}\text { Highest conversion (92\%) } \\
\text { achieved at } 310^{\circ} \mathrm{C}\end{array}$ & 4000 & [35] \\
\hline $\begin{array}{l}\mathrm{Pt}(2 \mathrm{wt} . \%) / \mathrm{CeO}_{2^{-}} \\
\mathrm{Al}_{2} \mathrm{O}_{3}\end{array}$ & $180-340$ & $\begin{array}{l}4.5 \text { vol\% } \mathrm{CO}, 31.1 \\
\mathrm{kPa} \text { steam in } \\
\text { balanced in } \mathrm{N}_{2}\end{array}$ & $\begin{array}{l}\text { Highest conversion }(93 \%) \\
\text { achieved at } 220^{\circ} \mathrm{C}\end{array}$ & 4000 & [35] \\
\hline $\mathrm{Ni} / \mathrm{C}$ & $140-300$ & $\begin{array}{l}1.75 \% \mathrm{CO}, 35.92 \% \\
\mathrm{H}_{2} \mathrm{O} \text {, balanced in } \\
\mathrm{He}\end{array}$ & $\begin{array}{l}\text { Highest conversion (93\%) } \\
\text { achieved at } 240{ }^{\circ} \mathrm{C}\end{array}$ & 10000 & [5] \\
\hline $\mathrm{Ni}-20 \% \mathrm{CeO}_{2} / \mathrm{C}$ & $140-300$ & $\begin{array}{l}1.75 \% \mathrm{CO}, 35.92 \% \\
\mathrm{H}_{2} \mathrm{O} \text {, balanced in } \\
\mathrm{He}\end{array}$ & $\begin{array}{l}\text { Highest conversion (93\%) } \\
\text { achieved at } 2400^{\circ} \mathrm{C}\end{array}$ & 10000 & [5] \\
\hline $\mathrm{Cu} / \mathrm{CeAl}$ & $200-400$ & $\begin{array}{l}5 \mathrm{~mol} \% \mathrm{CO}, 25 \\
\text { mol } \% \mathrm{H}_{2} \mathrm{O} \text {, and } \\
\text { balanced in } \mathrm{He}\end{array}$ & $\begin{array}{l}\text { Highest conversion (95\%) } \\
\text { achieved at } 350^{\circ} \mathrm{C}\end{array}$ & 12000 & This work \\
\hline $1 \mathrm{Cu} 1 \mathrm{Ni} / \mathrm{CeAl}$ & $200-400$ & $\begin{array}{l}5 \mathrm{~mol} \% \mathrm{CO}, 25 \\
\text { mol\% } \mathrm{H}_{2} \mathrm{O} \text {, and } \\
\text { balanced in } \mathrm{He}\end{array}$ & $\begin{array}{l}\text { Highest conversion }(97 \%) \\
\text { achieved at } 380^{\circ} \mathrm{C}\end{array}$ & 12000 & This work \\
\hline
\end{tabular}

For sake of comparison with the state of the art catalysts, Table 3 showcases the maximum CO conversion levels of selected reference catalysts including, bimetallic $\mathrm{Ni}-\mathrm{Cu}$, commercial $\mathrm{Cu}$ $\mathrm{ZnO} / \mathrm{Al}_{2} \mathrm{O}_{3}$ and noble metal-based catalysts. It should be stated that such a comparison is not always straightforward given the multiple reaction conditions employed in available works in literature. Herein we have selected those works that employed similar reaction conditions as those used in this study. As shown in the table the catalysts presented in this study can be ranked as high performing catalysts for the medium temperature shift reaction. Clearly, benchmark catalysts and noble metal based system outperform our materials in the low-temperature range, however, our mono and bimetallic catalysts are very efficient for temperatures above $300{ }^{\circ} \mathrm{C}$ and clearly more efficient than reference bimetallic $\mathrm{Cu}-\mathrm{Ni}$ systems reported in the literature. In addition, the catalysts presented in this study performed at relatively high space velocities which may result beneficial to design compact reactors for portable applications.

In the context of the WGS reaction for hydrogen purification goals, the WGS unit is typically linked to the reformer outlet. Therefore, the influence of post reforming mixtures must be tested for the potential implementation of the developed catalysts in a WGS unit for portable applications. Figure 6 shows the results of the WGS tests under post reforming conditions for selected catalysts. 


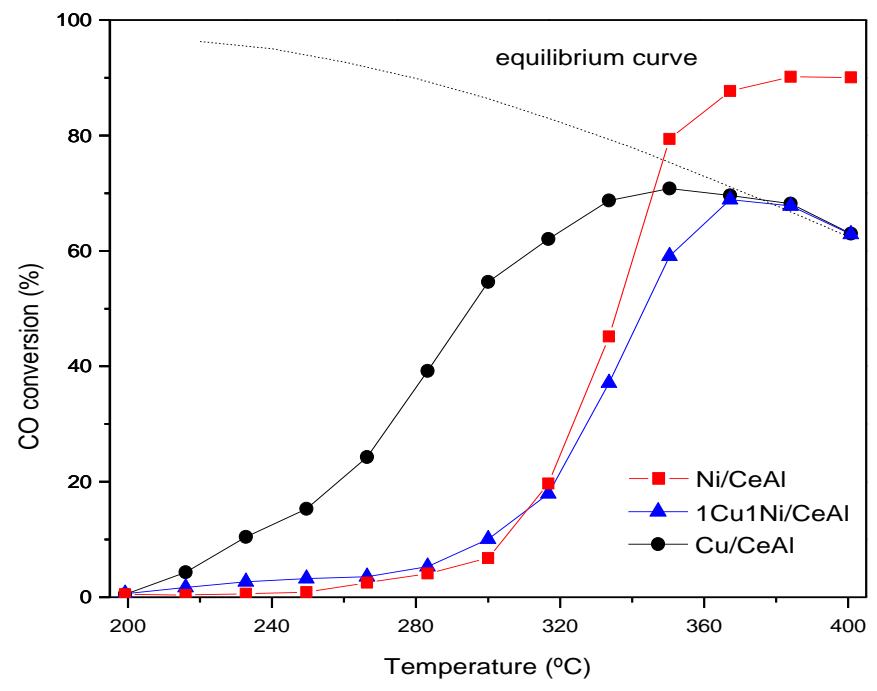

Figure 6. $\mathrm{CO}$ conversion as a function of temperature using a post-reforming mixture $\left(25 \%\right.$ vol. $\mathrm{H}_{2} \mathrm{O}$ $+8 \%$ vol. $\mathrm{CO}, 37 \% \mathrm{H}_{2}$ and $\left.8 \% \mathrm{CO}_{2}\right)$

As a general trend, the $\mathrm{CO}$ conversion is shifted towards higher temperatures as a consequence of Le Chatelier principle. Furthermore, this test corroborates the superiority of monometallic $\mathrm{Cu}$ in comparison with monometallic $\mathrm{Ni}$ and bimetallic $1 \mathrm{Cu}-1 \mathrm{Ni}$. Interestingly, the monometallic $\mathrm{Ni}$ overpassed the equilibrium conversion. This is actually an immediate reflect of the methanation reaction providing an alternative route for $\mathrm{CO}$ elimination. Such undesirable competitive reaction was enhanced under post-reforming conditions and discards the use of monometallic $\mathrm{Ni}$ as suitable WGS catalysts for a wide temperature range applications. The bimetallic catalysts composed by the $1 \mathrm{Cu}-$ $1 \mathrm{Ni}$ alloy still presented intermediate catalytic activity, reaching equilibrium conversion at $350{ }^{\circ} \mathrm{C}$ with no sign of methanation. It seems obvious that the bimetallic strategy works if we are aiming to improve the catalytic performance of a Ni-based catalyst; however, the bimetallic approach will worsen the behaviour of a $\mathrm{Cu}$ monometallic catalyst. As mentioned in the Introduction section, a Nibased material could be more suitable for the medium-high temperature range since the $\mathrm{Cu}$ nanoparticles could sinter. Under these particular conditions, it is then desirable to design a bimetallic catalyst ideally with a well-defined $\mathrm{Cu}-\mathrm{Ni}$ alloy. Nevertheless, if the target is the low-temperature shift reaction the use of mixed $\mathrm{Cu}-\mathrm{Ni}$ systems does not bring any advantage, and the monometallic $\mathrm{Cu}$ system must be the catalyst of choice. The catalyst selection will be therefore a non-trivial question since, depending on the fuel processor configuration (reforming - shift unit - CO-PrOx - fuel cell) [36], the heat integration may favour the selection of a medium temperature shift catalyst where monometallic copper will still be the obvious choice. For higher temperatures, the bimetallic $1 \mathrm{Cu}-1 \mathrm{Ni}$ could be an interesting choice, given the well-known tendency of monometallic copper for sintering at temperatures beyond $500{ }^{\circ} \mathrm{C}$.

In this study we have focused on the medium-temperature shift reaction and, aiming to test further the robustness of our best catalyst in the whole range of temperature, the monometallic $\mathrm{Cu}$ system was submitted to a long-term stability run including some start/stop cycles. The start/stop experiments replicate the start-up/shut-downs operations of a portable device (i.e. a hydrogen-powered vehicle) and they constitute a key test to identify efficient WGS catalysts for realistic applications. As shown in Figure 7 the activity of the catalyst was rather stable and only a drop from 58 to $48 \%$ was observed after more than $230 \mathrm{~h}$ of continuous operation with 5 series of start/stop cycles in between. This result is highly commendable especially if we consider that during the stop stages the feed kept passing through the catalytic bed (at room temperature), thus provoking the condensation of water on the catalyst's pores and potentially damaging the activity. The capacity of this catalyst to successfully 
withstand start-up/shut down operations is a great achievement and makes this material a promising catalyst to be further studied for its implementation in hydrogen fuel processors.

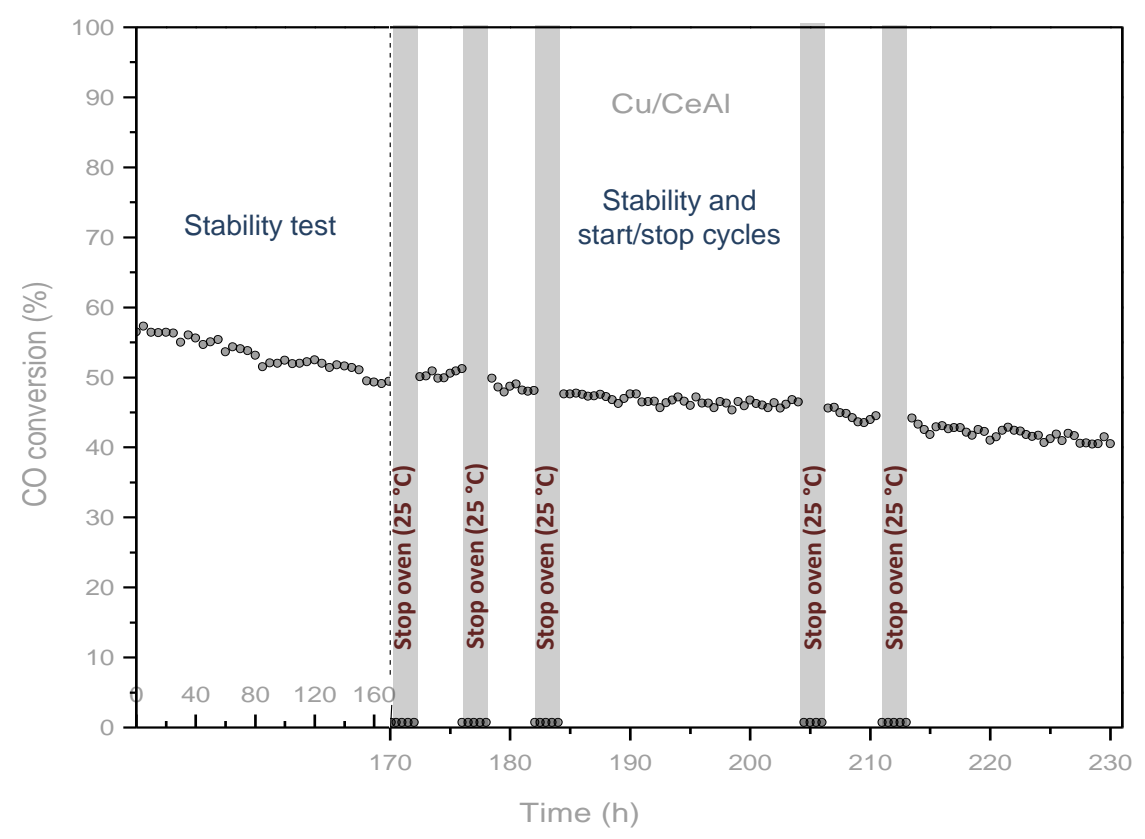

Figure 7. Long-term stability run at $280{ }^{\circ} \mathrm{C}$ with a post-reforming mixture $\left(25 \%\right.$ vol. $\mathrm{H}_{2} \mathrm{O}+8 \%$ vol. $\mathrm{CO}, 37 \% \mathrm{H}_{2}$ and $8 \% \mathrm{CO}_{2}$ ), including some start/stop cycles for the $\mathrm{Cu} / \mathrm{CeAl}$ catalyst.

The smooth deactivation observed is very likely related to $\mathrm{Cu}$ particles sintering. Indeed, we have calculated (using Scherrer equation) the $\mathrm{Cu}$ crystallite size of the $\mathrm{Cu} / \mathrm{CeAl}$ sample before (reduced sample) and after being tested it in the stability test. $\mathrm{Cu}$ metallic cluster presents a particle size of 15 $\mathrm{nm}$ in the reduced sample (diffractogram showed in Figure 1 (b)). After the $230 \mathrm{~h}$ of stability test with several start/stop cycles, the metallic $\mathrm{Cu}$ suffered a slight degree of sintering leading to particle sizes of $31 \mathrm{~nm}$ (diffractogram not shown) Also, very small diffraction peaks related to $\mathrm{CuO}$ appear after this stability test. The later could be due to the start-stop cycles where metallic $\mathrm{Cu}$ may undergo partial oxidation caused by interaction with liquid water during the shutdown stages. Both reasons (a certain degree of sintering and partial oxidation) account for the continuous activity depletion observed during the $230 \mathrm{~h}$ stability test.

In view of the results from Figure 7, it seems obvious that the comparison with bimetallic catalysts in terms of stability is needed. At the same time, such comparison must take place at higher temperatures since the bimetallic catalysts do not show sufficient activity at $280{ }^{\circ} \mathrm{C}$. Figure 8 depicts a comparative long-term stability test of the monometallic, $\mathrm{Cu} / \mathrm{CeAl}$, and bimetallic, $1 \mathrm{Cu} 1 \mathrm{Ni} / \mathrm{CeAl}$ sample including some start-stop cycles during the reaction. As shown in the figure the monometallic suffers for a clear activity decline even before the start-up/shutdowns operations. In fact, at this temperature $\mathrm{Cu}$ sintering is more favoured than in the previous experiments in Figure 7 and therefore there is a significantly stronger deactivation. Very interestingly, the bimetallic material is quite robust and displays a very stable behaviour during $170 \mathrm{~h}$ of reaction. However, upon performing 3 initial start-stop cycles the activity drops from around $60 \%$ of $\mathrm{CO}$ conversion to $c a .48 \%$ and then after a final cycle at $205 \mathrm{~h}$ the catalyst remarkably loss its activity. In any case, the superior stability of the bimetallic sample compared to the monometallic one reflects the benefits of the $\mathrm{Cu}-\mathrm{Ni}$ interaction which seems to go beyond an electronic effect as shown in our XPS data but also such synergy may help to prevent $\mathrm{Cu}$ clusters sintering leading to enhanced stability. 


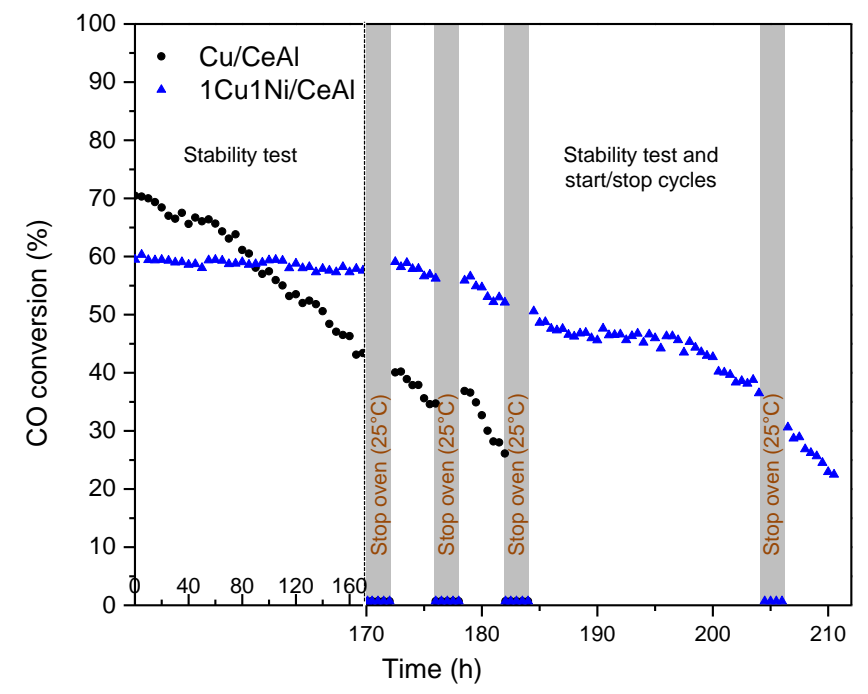

Figure 8. Long-term stability runs at $340{ }^{\circ} \mathrm{C}$ with a post-reforming mixture $\left(25 \%\right.$ vol. $\mathrm{H}_{2} \mathrm{O}+8 \%$ vol. $\mathrm{CO}, 37 \% \mathrm{H}_{2}$ and $8 \% \mathrm{CO}_{2}$ ), including some start/stop cycles for the $\mathrm{Cu} / \mathrm{CeAl}$ and $1 \mathrm{Cu} 1 \mathrm{Ni} / \mathrm{CeAl}$ catalysts.

\section{Conclusions}

Mono and bimetallic $\mathrm{Cu}-\mathrm{Ni}$-based catalysts display rather different performances in the WGS reaction. Despite what a priori could be envisaged in terms of the superior behaviour of the bimetallic systems, our study reveals that bimetallic formulations are not always advantageous. In fact, the monometallic $\mathrm{Cu}$ based catalyst has been found to be more active in both model and post-reforming WGS mixtures at low-medium temperatures than the bi-metallic $\mathrm{Cu}-\mathrm{Ni}$ systems. In addition, the monometallic $\mathrm{Cu}$ catalysts presented high stability and resistance towards transient startup/shutdowns operations - a necessary requisite of a shift catalyst for portable applications.

The monometallic Ni-based catalyst presented good levels of $\mathrm{CO}$ conversion but it also produces methane indicating hydrogen consumption via the undesired methanation reaction. The addition of $\mathrm{Cu}$ to $\mathrm{Ni}$ helps to suppress the methanation reaction since the $\mathrm{Cu}-\mathrm{Ni}$ alloy is completely selective towards the WGS. Among the screened bimetallic compositions it seems that $2 \mathrm{Cu}-1 \mathrm{Ni}$ and $1 \mathrm{Cu}-2 \mathrm{Ni}$ did not result advantageous at all for the shift process. Nevertheless, the bimetallic $1 \mathrm{Cu}-1 \mathrm{Ni}$ presents a good balance activity/selectivity/stability. In particular, this catalyst outperformed the stability of the monometallic $\mathrm{Cu}$ for medium-high temperature shift processes presenting some resistance toward start-stop situations.

Overall, this work showcases a strategy to design mono and bimetallic $\mathrm{Cu}-\mathrm{Ni}$ based for the WGS reaction. Although the intimate contact $\mathrm{Cu}-\mathrm{Ni}$ alters the physicochemical properties of the resulting catalysts, ultimately, the catalyst choice, its performance and suitability for long-term runs is determined by the metallic composition and the reaction conditions.

In fact, the monometallic $\mathrm{Cu}$-based catalyst has been found to be the best material in this study, showing excellent levels of medium-temperature conversion and enough stability for continuous and discontinuous operations. The bimetallic strategy works for $\mathrm{Ni}$ and, actually, the bimetallic catalyst is more interesting than the monometallic $\mathrm{Ni}$ if the $\mathrm{Cu}-\mathrm{Ni}$ alloy is achieved since the alloy suppresses the unwanted parallel methanation reaction which consumes hydrogen. Extreme bimetallic compositions such as $2 \mathrm{Cu}-1 \mathrm{Ni}$ and $1 \mathrm{Cu}-2 \mathrm{Ni}$ did not result advantageous at all for the shift process. 


\section{Acknowledgements}

Financial support for this work was provided by the EPSRC grants EP/J020184/2 and EP/R512904/1 as well as the Royal Society Research Grant RSGR1180353. The Spanish team acknowledges Ministerio de Economía, Industria y Competitividad of Spain (Project MAT2013-45008-P). L. PastorPerez acknowledges Generalitat Valenciana for her postdoctoral grant (APOSTD/2017). Sasol is kindly acknowledged for providing the support.

\section{References}

[1] Y. Hao, B.C. Gates. Activation of dimethyl gold complexes on $\mathrm{MgO}$ for $\mathrm{CO}$ oxidation: Removal of methyl ligands and formation of catalytically active gold clusters. J. Catal. 2009;263;83-91

[2] B. Dou, Y. Song, C. Wang, H. Chen, Y. Xu. Hydrogen production from catalytic steam reforming of biodiesel byproduct glycerol: Issues and challenges Renew. Sustain. Energy Rev. 2014;30;950-960.

[3] D.L. Trimm, Z.I. Önsan, Catal. Onboard fuel conversion for hydrogen-fuel-cell driven vehicles. Rev. Sci. Eng. 2001;43;31-84.

[4] F. Meshkani ,M. Rezaei, M. H. Aboonasr Shiraz, Preparation of high temperature water gas shift catalyst with coprecipitation method in microemulsion system, Chem. Eng. Res. Des. 2016;113;9-16.

[5] L. Pastor-Pérez, R. Buitrago-Sierra, A. Sepúlveda-Escribano, $\mathrm{CeO}_{2}$-promoted Ni/activated carbon catalysts for the water-gas shift (WGS) reaction. Int. J. Hydrog. Energy, 2014;39;17589- 17599

[6] F. Meshkani, M. Rezaei, Preparation of mesoporous nanocrystalline alkali promoted chromium free catalysts $\left(\mathrm{Fe}_{2} \mathrm{O}_{3}-\mathrm{Al}_{2} \mathrm{O}_{3}-\mathrm{NiO}\right)$ for a high temperature water gas shift reaction. RSC Adv., 2015;5; 9955-9964.

[7] M. Zhou, T. Nguyen-Minh Le, L. K. Huynh, B. Liu, Effects of structure and size of Ni nanocatalysts on hydrogen selectivity via water-gas-shift reaction-A first-principles-based kinetic study. Catal. Today 2017;280;210-219.

[8] J.H. Lin, P. Biswas, V.V. Guliants, S. Misture, Hydrogen production by water-gas shift reaction over bimetallic $\mathrm{Cu}-\mathrm{Ni}$ catalysts supported on La-doped mesoporous ceria. Appl. Catal. A: Gen. 2010;387;87-94.

[9] E.T. Saw, U. Oemar, X.R. Tan, Y. Du, a. Borgna, K. Hidajat, S. Kawi, Bimetallic Ni-Cu catalyst supported on $\mathrm{CeO} 2$ for high-temperature water-gas shift reaction: Methane suppression via enhanced CO adsorption. J. Catal. 2014;314;32-46.

[10] T. Liang, Y. Wang, M. Chen, Z. Yang, S. Liu, Z. Zhou, X. Li, Steam reforming of phenolethanol to produce hydrogen over bimetallic $\mathrm{NiCu}$ catalysts supported on sepiolite. Int. J. Hydrog. Energy, 2017;42;28233-28246.

[11] A.A. Lytkina, N.A. Zhilyaeva, M.M. Ermilova, N.V. Orekhova, A.B. Yaroslavtsev, Influence of the support structure and composition of $\mathrm{Ni}-\mathrm{Cu}$-based catalysts on hydrogen production by methanol steam reforming. Int. J. Hydrog. Energy, 2015;40;9677-9684.

[12] D. Li, M. Lu, K. Aragaki, M. Koike, Y. Nakagawa, K. Tomishige, Characterization and catalytic performance of hydrotalcite-derived $\mathrm{Ni}-\mathrm{Cu}$ alloy nanoparticles catalysts for steam reforming of 1methylnaphthalene. Appl. Catal. B: Env. 2016;192;171-181.

[13] Y. Shen, A.C. Lua, Synthesis of Ni and Ni-Cu supported on carbon nanotubes for hydrogen and carbon production by catalytic decomposition of methane. Appl. Catal. B: Env. 2015;164;61-69. 
[14] L.D. Rogatis, T. Montini, B. Lorenzut, P. Fornasiero, $\mathrm{Ni}_{\mathrm{x}} \mathrm{Cu}_{\mathrm{y}} / \mathrm{Al}_{2} \mathrm{O}_{3}$ based catalysts for hydrogen production. Energy Environ. Sci. 2008;1;501-509.

[15] L.C. Chen, S.D. Lin, The ethanol steam reforming over $\mathrm{Cu}-\mathrm{Ni} / \mathrm{SiO}_{2}$ catalysts: Effect of $\mathrm{Cu} / \mathrm{Ni}$ ratio. Appl. Catal. B: Env. 2011;106;639-649.

[16] K.C. Khulbe, R.S. Mann, Nature of Ni-Cu alloys and their role in chemical reactions. Catal. Rev. -Sci. Eng. 1982;24;311-328.

[17] J.H. Sinfelt, J.L. Carter, D.J.C. Yates, Catalytic hydrogenolysis and dehydrogenation over copper-nickel alloys. J. Catal. 1974;24;283-296.

[18] A.R. Naghash, T.H. Etsell, S. Xu, XRD and XPS Study of $\mathrm{Cu}-\mathrm{Ni}$ Interactions on reduced copper-nickel-aluminum oxide solid solution catalysts. Chem. Mater. 2006;18;2480-2488.

[19] T.R. Reina, S. Ivanova, M.A. Centeno, J.A. Odriozola, The role of $\mathrm{Au}, \mathrm{Cu} \& \mathrm{CeO}_{2}$ and their interactions for an enhanced WGS performance. Appl. Catal. B: Env. 2016;187;98-107.

[20] H.E. Swift, F.E. Lutinski, W.L. Kehl, Investigation of the metallic phases in reduced, impregnated nickel and nickel-copper silica-alumina catalysts. J. Phys. Chem. 1965;69;3268-3274.

[21] A. Trovarelli, Catalytic properties of ceria and $\mathrm{CeO}_{2}$-containing materials. Catal. Rev. - Sci. Eng., 1996;38;439-520.

[22] S. Damyanova, C.A. Perez, M. Schmal, J.M.C. Bueno, Characterization of ceria-coated alumina carrier. Appl. Catal., A: Gen. 2002;234;271-282.

[23] R. Molina, G. Poncelet, $\alpha$-Alumina-supported nickel catalysts prepared from nickel acetylacetonate: A TPR study. J. Catal. 1998;173;257-267.

[24] A. Piras, A. Trovarelli, G. Dolcetti, Remarkable stabilization of transition alumina operated by ceria under reducing and redox conditions. Appl. Catal., B: Env. 2000;28;L77-L81.

[25] P. Ratnasamy, D. Srinivas, C.V.V. Satyanarayana, P. Manikandan, R.S. Senthil Kumaran, M. Sachin, V.N. Shetti, Influence of the support on the preferential oxidation of $\mathrm{CO}$ in hydrogen-rich steam reformates over the $\mathrm{CuO}-\mathrm{CeO}_{2}-\mathrm{ZrO}_{2}$ system. J. Catal. 2004;221;455-465.

[26] X. Zheng, X. Zhang, X. Wang, S. Wang, S. Wu, Preparation and characterization of $\mathrm{CuO} / \mathrm{CeO}_{2}$ catalysts and their applications in low-temperature CO oxidation. Appl. Catal. A: Gen. 2005;295;142149.

[27] A.J. Vizcaíno, A. Carrero, J.A. Calles, Hydrogen production by ethanol steam reforming over Cu-Ni supported catalysts. Int. J. Hydrog. Energy 2007;32;1450-1461.

[28] P. Li, J. Liu, N. Nag, P.A. Crozier, In situ preparation of $\mathrm{Ni}-\mathrm{Cu} / \mathrm{TiO}_{2}$ bimetallic catalysts. J. Catal., 2009;262;73-82.

[29] K. Kishi, Y. Motoyoshi, S. Ikeda, Deposition of nickel from $\mathrm{Ni}(\mathrm{CO})_{4}$ on palladium and iron surfaces studied by X-ray photoelectron spectroscopy. Surf. Sci. 1981;105;313-324.

[30] G. Treglia, M.C. Desjonqueres, F. Duncastelle, D. Spanjaad, Correlation effects on Auger spectra in unfilled d band metals. J. Phys. 1981;C14;4347-4355.

[31] C. Price, L. Pastor-Pérez, E. le Saché, A. Sepúlveda-Escribano, T.R. Reina, Highly active Cu$\mathrm{ZnO}$ catalysts for the WGS reaction at medium-high space velocities: Effect of the support composition. Int. J. Hydrog. Energy 2017;42;10747-10751. 
[32] E.T. Saw, U. Oemar, M.L. Ang, K. Hidajat, S. Kawi, Highly Active and Stable Bimetallic Nickel-Copper Core-Ceria Shell Catalyst for High-Temperature Water-Gas Shift Reaction. ChemCatChem. 2015;7;3358 - 3367.

[33] O. Arbeláez, T.R. Reina, S. Ivanova, F. Bustamante, A.L. Villa, M.A. Centeno, J.A. Odriozola, Mono and bimetallic $\mathrm{Cu}-\mathrm{Ni}$ structured catalysts for the water gas shift reaction. Mono and bimetallic $\mathrm{Cu}-\mathrm{Ni}$ structured catalysts for the water-gas shift reaction. Appl. Catal. A: Gen. 2015;497;1-9.

[34] T. Tabakova, V. Idakiev, J. Papavasiliou, G. Avgouropoulos, T. Ioannides, Effect of additives on the WGS activity of combustion synthesized $\mathrm{CuO} / \mathrm{CeO}_{2}$ catalysts. Catal. Commun. 2007;8;101-106.

[35] M. Gonzalez Castaño, T. R. Reina, S. Ivanova, M. A. Centeno, J. A. Odriozola, Pt vs. Au in water-gas shift reaction. J. Catal. 2014;314;1-9.

[36] T.R. Reina, E. Papadopoulou, S. Palma, S. Ivanova, M.A. Centeno, T. Loannides, J.A. Odriozola, Appl. Catal. B: Env. 2014;150-151;554-563. 